\title{
Regeneration of Hydrotreating and FCC Catalysts
}
M. A. Gerber
J. L. Fulton
J. G. Frye
L. J. Silva
L. E. Bowman
C. M. Wai ${ }^{(a)}$

September 1999

Prepared for

the U.S. Department of Energy

under Contract DE-AC06-76RLO 1830

Pacific Northwest National Laboratory

Richland, Washington 99352

(a) University of Idaho

Moscow, Idaho 83844 



\section{DISCLAIMER}

This report was prepared as an account of work sponsored by an agency of the United States Government. Neither the United States Government nor any agency thereof, nor any of their employees, make any warranty, express or implied, or assumes any legal liability or responsibility for the accuracy, completeness, or usefulness of any information, apparatus, product, or process disclosed, or represents that its use would not infringe privately owned rights. Reference herein to any specific commercial product, process, or service by trade name, trademark, manufacturer, or otherwise does not necessarily constitute or imply its endorsement, recommendation, or favoring by the United States Government or any agency thereof. The views and opinions of authors expressed herein do not necessarily state or reflect those of the United States Government or any agency thereof. 


\section{DISCLAIMER}

Portions of this document may be illegible in electronic image products. Images are produced from the best available original document. 


\section{Summary and Conclusions}

Hydrotreating, hydrocracking, and fluid catalytic cracking (FCC) catalysts are important components of petroleum refining processes. Hydrotreating and hydrocracking catalysts are used to improve the yield of high-quality light oil fractions from heavier crude oil and petroleum feedstocks containing high levels of impurities. FCC catalysts improve the yield of higher octane gasoline from crude oil.

Residuum hydrotreating and cracking catalysts are susceptible to irreversible deactivation caused by adsorption of sulfur and by metals impurities, such as vanadium and nickel. The gradual buildup of these impurities in a hydrotreating catalyst eventually plugs the pores and deactivates it. Nickel and vanadium adversely affect the behavior of cracking catalysts, reducing product yield and quality.

Replacing deactivated catalysts represents a significant cost in petroleum refining. Equally important are the costs and potential liabilities associated with treating and disposing spent catalysts. For example, recent U.S. Environmental Protection Agency rulings have listed spent hydrotreating and hydrorefining catalysts as hazardous wastes. FCC catalysts, though more easily disposed of as road-base or as filler in asphalt and cement, are still an economic concem mainly because of the large volumes of spent catalysts generated.

New processes are being considered to increase the useful life of catalysts or for meeting more stringent disposal requirements for spent catalysts containing metals. This report discusses a collaborative effort between Pacific Northwest National Laboratory (PNNL) and Phillips Petroleum, Inc., to identify promising chemical processes for removing metals adhered to spent hydrodesulfurization (HDS, a type of hydrotreating catalyst) and FCC catalysts. This study, conducted by PNNL, was funded by the U.S. Department of Energy's Bartlesville Project Office.

Fresh and spent catalysts were provided by Phillips Petroleum. The FCC catalyst was a rare-earth exchanged $\mathrm{Y}$ zeolite in a silica-alumina matrix. X-ray fluorescence analyses showed that the rare earths used in preparing the catalysts were a mixture of lanthanum and cerium. Antimony found in the spent catalyst was added during operation of the FCC unit as a way to suppress the adverse effects of deposited nickel. The fresh HDS samples consisted of sulfided nickel and molybdenum on an alumina support. The spent catalyst showed nearly $10 \%$ vanadium on the catalyst and a modest increase in nickel and sulfur on the catalyst as a result of operations. Hydrocracking catalysts were not available for this study.

Four processes were evaluated: electrochemical dissolution, chemical extraction using complexants, chemical extraction under hydrothermal conditions, and supercritical carbon dioxide extraction. The results of the experiments and a literature review on related research (provided in the appendix) did not show promise for aqueous phase processing to regenerate the catalysts, because either the catalyst support was altered or catalyst materials, such as molybdenum and lanthanum, were also removed. Some merit to nonaqueous phase treatment may be seen; for example, the supercritical $\mathrm{CO}_{2}$ extraction experiments showed good vanadium and modest nickel extraction without altering the $\mathrm{Si} / \mathrm{Al}$ ratio of the catalyst. One issue with this approach may be the cost of the extractants. However, less expensive extractants may be available. The literature review identified carbonyl treatment as a possible method for removing nickel and iron from the FCC catalyst. In this process, the spent catalyst would first be reduced with hydrogen, followed by gas phase extraction using $\mathrm{CO}$ to extract nickel and iron carbonyls. 
Aqueous processing may be practical for recovering metals from spent hydrotreating catalyst. Catalyst dissolution using nitric acid along with an oxidant $\left(\mathrm{Ce}^{+4}\right)$ was demonstrated during the tests. Alkaline leaching using a combination of $\mathrm{NH}_{4} \mathrm{OH}$ and $\mathrm{H}_{2} \mathrm{O}_{2}$ achieved good recovery of $\mathrm{V}$, $\mathrm{Ni}$, and $\mathrm{Mo}$ without dissolving the alumina support. This approach also has the advantage of simpler processing to recover the metals. The results and conclusions from the individual processes investigated are summarized here.

\section{Electrochemical Dissolution}

The initial focus of the project was to evaluate an electrochemical process to simultaneously oxidize carbon on the spent catalyst and leach metals and sulfur from spent FCC and HDS catalyst supports. Conceptually, the electrochemical process used the $\mathrm{Ce}^{+4}$ ion as an oxidant in a solution of nitric acid to keep the ion in solution. The $\mathrm{Ce}^{+4}$ ion would be regenerated using an electrolytic cell coupled with petrochemical regeneration.

The electrochemical dissolution/extraction experiments separately investigated chemical oxidation and regeneration steps. In experiments using a $2 \mathrm{M} \mathrm{HNO}_{3} / 0.5 \mathrm{M} \mathrm{Ce}^{+4}$ solution at $70^{\circ} \mathrm{C}$ for 10 or more hours, up to $81 \% \mathrm{~V}, 45 \% \mathrm{Ni}$, and $69 \% \mathrm{Fe}$ removal was achieved. There was also clear evidence that most of the aluminum and lanthanum was removed (about $81 \%$ and $87 \%$, respectively). These results were comparable to those achieved using $8 \mathrm{M} \mathrm{HNO}_{3}$ under the same conditions. Using the same solution, but under refluxing conditions $\left(110^{\circ} \mathrm{C}\right)$, at $21 \mathrm{hr}$ achieved $100 \% \mathrm{~V}, 85 \% \mathrm{Ni}$, and $89 \% \mathrm{Fe}, 88 \% \mathrm{Al}$, and $93 \% \mathrm{La}$ removal. These experiments show regeneration of the FCC catalyst using selective leaching with nitric acid and $\mathrm{Ce}^{+4}$ is not practical because of the loss of aluminum and lanthanum from the catalyst. While good recovery of the lanthanum and heavy metals was achieved, it is unlikely the amounts would be sufficient to be economically viable.

Complete dissolution of spent hydrotreating catalyst could be accomplished in a $2 \mathrm{M}$ $\mathrm{HNO}_{3} / 0.5 \mathrm{M} \mathrm{Ce}^{+4}$ solution under refluxing conditions $\left(110^{\circ} \mathrm{C}\right)$ for about $14 \mathrm{hr}$. This dissolution can be compared to achieving $99 \%$ dissolution of $\mathrm{FCC}$ catalyst in concentrated $\mathrm{HNO}_{3}$ under refluxing conditions $\left(120^{\circ} \mathrm{C}\right)$ for $16 \mathrm{hr}$. Using the same $2 \mathrm{M} \mathrm{HNO}_{3} / 0.5 \mathrm{M} \mathrm{Ce}^{+4}$ solution at lower temperatures achieved some selective leaching of $\mathrm{Ni}, \mathrm{Fe}, \mathrm{Mo}, \mathrm{V}$ and $\mathrm{S}$ over aluminum, but there was significant catalyst loss at temperatures of $50^{\circ} \mathrm{C}$ and above and for long leaching times.

Experiments were conducted using electrochemical cells to determine the conditions needed to regenerate the $\mathrm{Ce}^{+4}$ ion. In some of the earlier tests using an $\mathrm{H}$-cell, the ceric ion was successfully regenerated using both cationic and anionic membranes, provided either nitric acid or a nitrate salt was added to the anolyte to minimize ceric ion migration to the cathode. This was an artifact of the cell configuration, which was operated in batch mode. Gas evolution at the anode, attributed to oxygen generation, was noted. A later test using a microcell also confirmed $\mathrm{Ce}^{+4}$ regeneration under continuous flow conditions. Six additional tests were conducted under continuous flow conditions using the microcell, but under conditions of near-neutral $\mathrm{pH}$ $(\mathrm{pH}=5.6)$. These conditions were investigated because lower $\mathrm{pH}$ caused dealumination of the catalyst supports. $\mathrm{Ce}^{+4}$ regeneration was also achieved under these conditions. However, the current efficiency under these conditions was very low $(<0.2 \%)$ and was generated at the anode. 


\section{Chemical Extraction Using Complexants}

Complexants tested for FCC catalysts included maleic acid, disodium EDTA, ammonium chloride, ammonium hydroxide, and ammonium citrate. Extraction using $30 \%$ hydrogen peroxide was also performed. Only the solution containing ammonium hydroxide $(0.5 \mathrm{M}$ $\mathrm{NH}_{4} \mathrm{OH}, 0.5 \mathrm{M} \mathrm{NH}_{4} \mathrm{Cl}$ mixture) and the hydrogen peroxide mixture avoided significant dealumination of the FCC catalyst, and only the hydrogen peroxide solution avoided significant removal of lanthanum. However, the hydrogen peroxide solution had no notable effect on the catalyst other than to remove about $22 \%$ of the vanadium, and cause a qualitative removal of coke on the catalyst.

Two tests using citric acid and one test using $30 \% \mathrm{H}_{2} \mathrm{O}_{2}$ were conducted using $\mathrm{HDS}$ catalyst that had previously been extracted with heptane and calcined to remove soluble hydrocarbons and coke from the spent catalyst. A 2-hr leaching with $0.1 \mathrm{M}$ citric acid at room temperature and $90^{\circ} \mathrm{C}$ resulted in only $73 \%$ and $48 \%$ recovery of the catalyst. Furthermore, citric acid at room temperature did not appear to remove either nickel or vanadium, although there was about $70 \%$ removal of sulfur and $40 \%$ removal of iron. There appeared to be selective removal of nickel, vanadium, molybdenum, iron, and sulfur from the HDS catalyst using a 2-hr leach with $30 \%$ $\mathrm{H}_{2} \mathrm{O}_{2}$ at room temperature. However, only $54 \%$ of the catalyst was recovered, and recovered particles were much smaller than those in the original sample.

Five tests were conducted using ammonia and hydrogen peroxide mixtures to selectively extract vanadium and nickel from heptane-extracted HDS catalyst. Ammonia is known to complex nickel, and has been used in wet air oxidation conditions to extract nickel from nickel sulfide ore. $\mathrm{H}_{2} \mathrm{O}_{2}$ was used instead of air to avoid the need to operate at high pressure. The combination of both reagents was found to selectively extract $\mathrm{V}, \mathrm{Ni}, \mathrm{Mo}$, and $\mathrm{S}$ from the HDS catalyst, leaving behind the alumina support and iron, although with significant molybdenum removal, this approach cannot be used to regenerate the catalyst. However, high recovery levels of vanadium nickel and molybdenum without coextraction of aluminum does produce a solution amenable to recovery of these metals. Extraction efficiencies greater than $80 \%$ for all three metals occurred using a 3-hr leach with $1.0 \mathrm{M} \mathrm{NH}_{4} \mathrm{OH}$, followed by a $1-\mathrm{hr}$ leach using a $1.0 \mathrm{M} \mathrm{NH}_{4} \mathrm{OH}, 1.0 \mathrm{M}$ $\mathrm{H}_{2} \mathrm{O}_{2}$ mixture.

\section{Chemical Extraction Under Hydrothermal Conditions}

These tests were conducted to determine if significantly higher extraction temperatures (up to $175^{\circ} \mathrm{C}$ ) could selectively extract nickel and vanadium. The hydrothermal conditions used for the tests included water with and without the addition of $\mathrm{H}_{2} \mathrm{O}_{2}$ or $\mathrm{Ce}^{+4}$. Oxidants were considered because of the apparent extraction of vanadium at room temperature using $\mathrm{H}_{2} \mathrm{O}_{2}$ in previous experiments. Hydrothermal processing under the conditions investigated did not improve vanadium removal nor did it cause selective nickel removal.

\section{Supercritical $\mathrm{CO}_{2}$ Extraction}

Supercritical $\mathrm{CO}_{2}$ extraction experiments were conducted to evaluate the use of selected dithiocarbamates, $\beta$-diketones, and porphyrins as chelating agents. Trace quantities of $\mathrm{HNO}_{3}$ and cerium nitrates were added in some experiments. Extractions were conducted for 15 min using a selected extractant or combination of extractants in a mixture of $5 \%$ methanol in $\mathrm{CO}_{2}$. It was 
found that $56 \%$ removal of vanadium could be achieved with lithium bis(trifluoroethyl)dithiocarbamate (LiFDDC), which was the best extractant. More modest recoveries of nickel were also achieved with one of the porphyrins (29\%) and with LiFDDC mixed with a Ce ${ }^{+4}$ compound $\left(\mathrm{NH}_{4}\right)_{2} \mathrm{Ce}\left(\mathrm{NO}_{3}\right)_{6}(32 \%)$. None of the individual extractants showed good simultaneous extraction for both $\mathrm{V}$ and $\mathrm{Ni}$, and only one combination (LiFDDC and hexafluoroacetylacetone) achieved significant extraction of both $(19 \% \mathrm{~V}$ and $13 \% \mathrm{Ni})$. With the exception of two experiments, the $\mathrm{Si} / \mathrm{Al}$ ratio remained unchanged during the extractions, suggesting that the catalyst support was unaffected. 


\section{Contents}

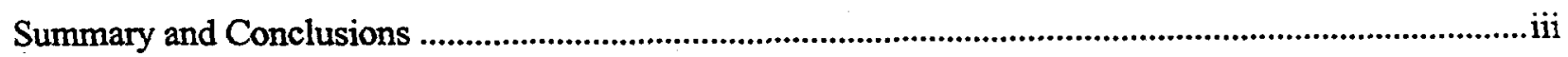

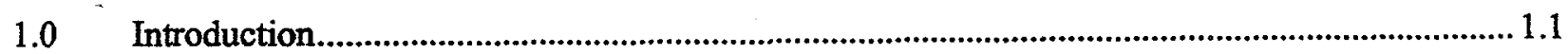

1.1 Catalytic Processes and Catalyst Deactivation ..................................................................... 1.1

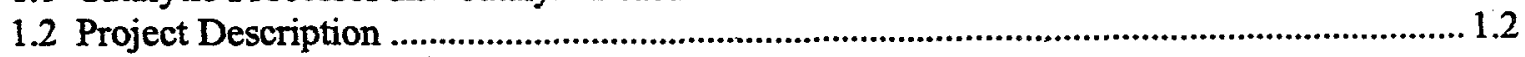

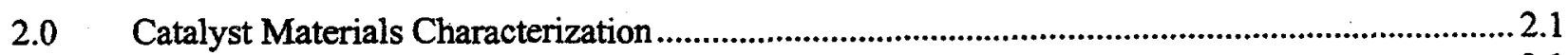

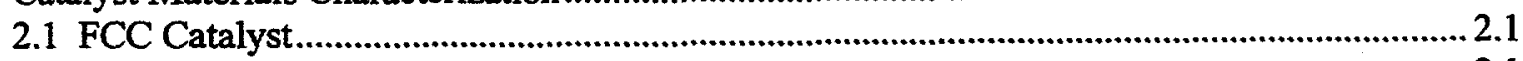

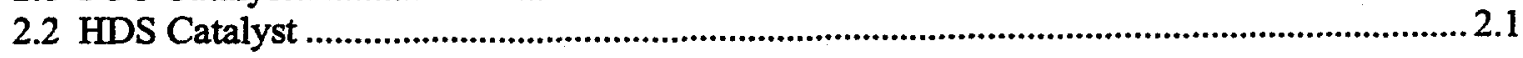

3.0 Electrochemical Dissolution for Processing Spent Catalyst ........................................................ 3.1

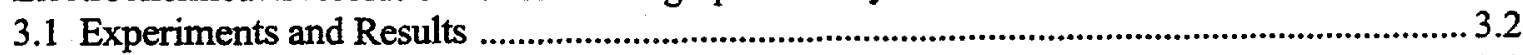

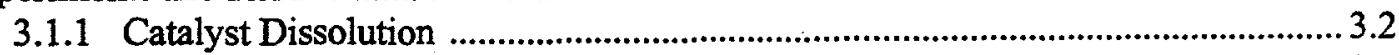

3.1.2 Electrochemical Ceric Ion Regeneration ....................................................... 3.4

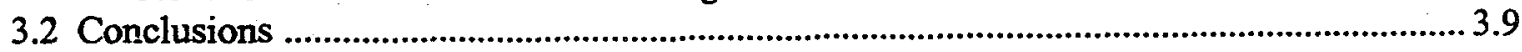

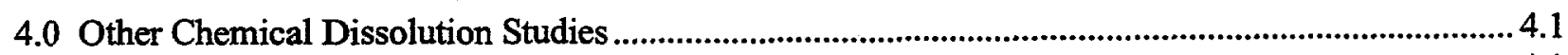

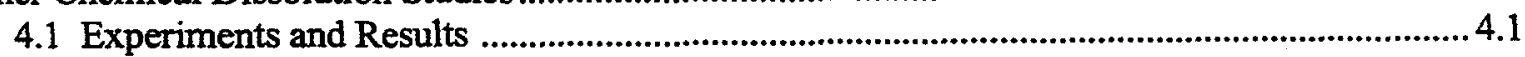

4.1.1 Batch Contact Tests with FCC Catalysts .......................................................... 4.1

4.1.2 Batch Contact Test with HDS Catalyst ............................................................. 4.1

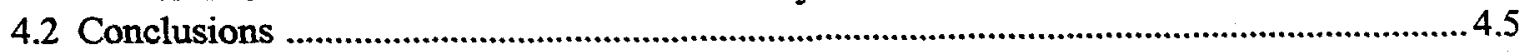

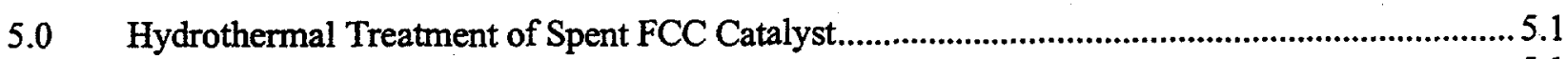

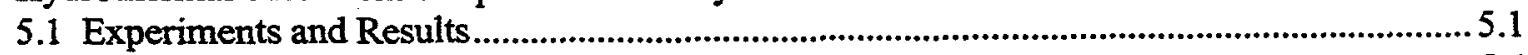

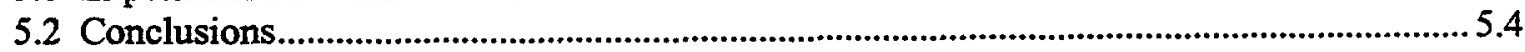

6.0 Supercritical Fluid Extraction of Nickel and Vanadium from Contaminated Zeolite

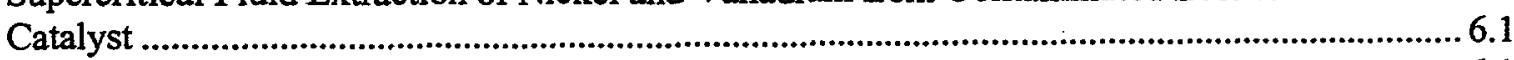

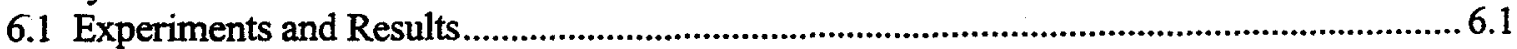

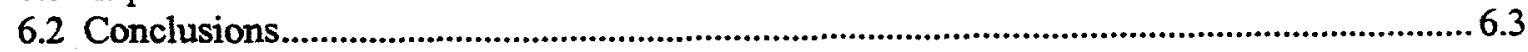

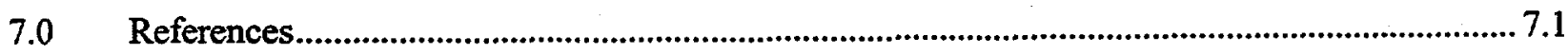

Appendix, Regeneration of Catalysts Used in Processing Residual-Oil-Type Feedstocks ...................... A.1 


\section{Tables}

2.1 XRF Analysis of Selected Constituents in an FCC Catalyst ................................................. 2.1

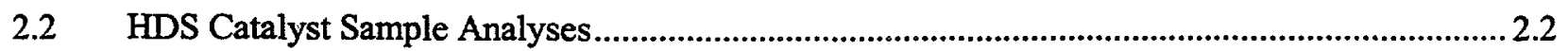

3.1 Results of Batch Contact Experiments of $\mathrm{FCC}$ Catalysts Using $\mathrm{HNO}_{3}$ and $\mathrm{HNO}_{3} / \mathrm{Ce}^{+4}$

Solutions

3.2 XRF Results of Solids from Spent HDS Catalyst Treatments.................................................. 3.5

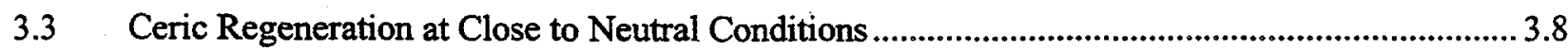

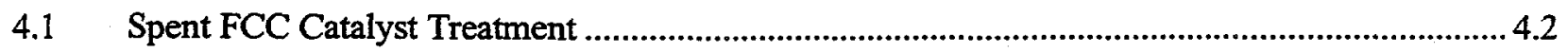

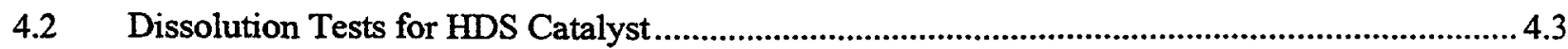

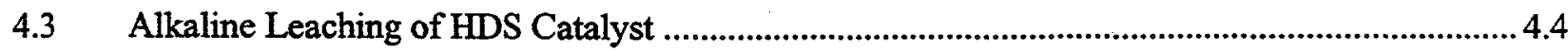

5.1 Summary of the Experimental Parameters and Results for the First Set of Experiments............ 5.2

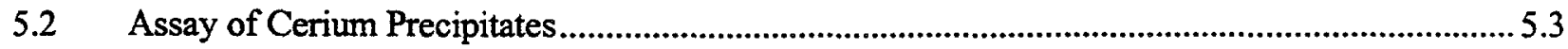

5.3 Effect of Higher Extraction Temperature Using Deionized Water...........................................5.3

5.4 Summary of Single Extractions with Neat Water at Different Temperatures

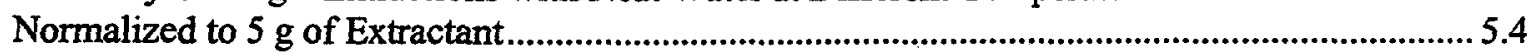

6.1 Test Conditions for Supercritical Fluid Extraction Experiments...............................................6.2

6.2 Summary of Experimental Results for Supercritical Fluid Extraction Experiments .................... 6.2 


\section{Figures}

Electrochemical Cell Showing $\mathrm{H}^{+}, \mathrm{e}^{-}$, and Cerium Ion Transport ............................................... 3.2

3.2 Batch Contact of Spent FCC Catalyst in Ceric Nitrate/Nitric Acid Solution .............................. 3.4

3.3 H-Type Cell Used for Tests on Electrochemical Ceric Ion Regeneration .................................... 3.6

3.4 Potentiometric Titration Curve Showing Solution Potential as a Function of Ferrous Ion Concentration.

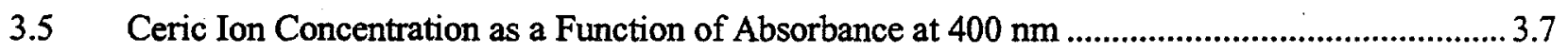

5.1 Diagram of Apparatus Used for Hydrothermal Extractions .................................................... 5.2 


\subsection{Introduction}

Catalytic processes are used in crude oil refining to convert the high boiling point fractions of the crude (atmospheric and vacuum residual oil fractions and asphalt pitch) into lower boiling materials that become fuel oil, gasoline, diesel, and jet fuels. However, applying these catalytic processes is complicated by relatively high concentrations of heavy metals (i.e., vanadium and nickel) in the oil. These metals affect the lifetimes and behavior of the catalysts during refinery operations and also become a factor in disposing of spent catalysts. Some spent catalysts are used in asphalt, as road-base, or in manufacturing cement, but there are limits on the metals content in these applications (Higgins 1996). Others that have typically been sent to a metals reclaimer or to a landfill have recently been listed as hazardous wastes by the U.S. Environmental Protection Agency (EPA) (Oil \& Gas Journal 1998). Consequently, various alternatives are being considered for meeting stricter disposal regulations, reducing costs, and improving catalyst performance.

The work discussed in this report mainly focused on testing and evaluating promising technologies for separating metals from spent catalysts. A review was also made to identify other potential methods for removing the metals that would allow the catalysts to be regenerated. This work was a collaborative effort between Pacific Northwest National Laboratory (PNNL) and Phillips Petroleum, Inc., and was funded by the U.S. Department of Energy's Bartlesville Project Office. Section 1.1 gives a brief overview of the effects of metals on the catalytic processes. Section 1.2 describes the study reported here.

\subsection{Catalytic Processes and Catalyst Deactivation}

The principal catalytic processes used in crude oil refining include hydrocracking, hydrotreating, and fluid catalytic cracking (FCC). Hydrocracking processes help convert residual oil into lower boiling point fractions. These processes are particularly suited for feedstocks high in coke precursors (aromatics and polyaromatics and asphaltenes) sulfur, nitrogen, and metals. Hydrocracking processes can be tailored to maximize different products such as low sulfur fuel oil, lubricating oils, jet fuel, and diesel fuel. However, hydrocracking catalysts were not available for study in this project.

The catalyst processes addressed in this effort involved hydrotreating and FCC. Hydrotreating processes are used primarily for reducing sulfur in petroleum products. In addition, the processes are used to reduce the nitrogen and oxygen content present in some crude oils, as well as to remove metals. Hydrotreating processes are also specified as hydrodesulfurization (HDS), hydrodenitrogenation (HDN), hydrogenolysis $(\mathrm{HDH})$, and hydrodemetallization (HDM), depending on the characteristics of the feedstock, although all subprocesses take place to varying degrees on different hydrotreating catalysts. Hydrotreating catalysts are designed to minimize cracking reactions as a way to minimize hydrogen consumption.

In the hydrotreating (and hydrocracking) processes, catalytic coke production is minimized by operating the processes at high hydrogen pressures, thereby increasing overall yield. While both these catalysts can tolerate metal deposits on the order of several percent of the catalyst weight, eventually they become inactive when the pores plug. A typical hydrotreating catalyst may last less than a year.

Fluid catalytic cracking is used to increase the yield of gasoline from light and heavy gas oils, naphtha, and some residual oil. Compared to the older thermal cracking processes, FCC produces hydrocarbons with high anti-knock properties, reduces the formation of olefinic hydrocarbons (which form gum 
deposits in gasoline), and reduces the formation of methane and $\mathrm{C}_{2}$ hydrocarbon gases in favor $\mathrm{C}_{3}$ and $\mathrm{C}_{4}$ hydrocarbons used in liquefied petroleum gas (LPG). The main limitation of the FCC process is it produces coke deposits that quickly deactivate the catalyst, thus requiring it to be regenerated. It is also poisoned by metals in the feed to the extent that it must be replaced on a daily basis. The FCC catalyst generally requires pretreatment of the oil by the other catalytic processes in order to minimize its exposure to metals.

FCC catalysts do not operate in a hydrogen environment and work by promoting cracking to produce branched hydrocarbons that are good in gasoline blends. However, even small quantities of metal deposits (on the order of hundreds of ppm) catalyze coke production, thereby reducing yield, and change the composition of the oil to one that is less favorable for gasoline blending.

\subsection{Project Description}

The main focus of the research presented in this report was to develop an electrochemical oxidation process to completely dissolve spent FCC and hydrotreating catalysts in a single step, including coke and nonvolatile hydrocarbons. Complete dissolution of spent catalyst followed by isolation of specific components would provide the opportunity to reclaim rare earths, nickel, and vanadium by using subsequent processing steps to separate these constituents from the solution. A secondary goal was to identify other, less severe, processes that would selectively separate nickel and vanadium from the catalysts without harming the catalyst support and, in turn, prolong the useful life of the catalyst. This report summarizes results of the research on electrochemical dissolution, as well as chemical extraction using complexants, chemical extraction under hydrothermal conditions, and supercritical carbon dioxide extraction.

The catalyst materials used in the tests are described in Section 2.0. Section 3.0 provides the results of the experiments on electrochemical dissolution, and the other chemical dissolution tests are discussed in Section 4.0. Section 5.0 describes the tests on hydrothermal treatments of spent FCC catalysts, and Section 6.0 discusses supercritical $\mathrm{CO}_{2}$ extraction of nickel and vanadium from spent FCC catalyst.

The appendix provides an overview of other research on the demetallization of FCC and hydrotreating catalysts, although no processes have yet been shown to be commercially successful. 


\subsection{Catalyst Materials Characterization}

For this study, FCC and HDS catalysts, provided by Phillips Petroleum, were used in various experiments at PNNL. These materials are described below.

\subsection{FCC Catalyst}

The FCC catalyst was a rare-earth exchanged Y-zeolite in a silica-alumina matrix. X-ray fluorescence (XRF) analyses of the fresh and spent catalysts are shown in Table 2.1. Two separate sets of analyses of spent catalyst were made to determine its heterogeneity. The second set included triplicates to reduce error in the measurements.

Table 2.1. XRF Analysis of Selected Constituents in an FCC Catalyst

\begin{tabular}{|c|c|c|c|}
\hline XRF, ppm & Fresh Catalyst & $\begin{array}{c}\text { Spent Catalyst } \\
\text { (1993 analysis) }\end{array}$ & $\begin{array}{c}\text { Spent Catalyst } \\
\text { (1994 analysis, } \\
\text { average of 3 samples) }\end{array}$ \\
\hline $\mathrm{Al}$ & 141,100 & 169,000 & 161,467 \\
\hline $\mathrm{Si}$ & 260,000 & 303,000 & 332,000 \\
\hline $\mathrm{V}$ & $<33$ & 899 & 1,455 \\
\hline $\mathrm{Ni}$ & 31 & 4,690 & 3,930 \\
\hline $\mathrm{Fe}$ & 3,880 & 6,800 & 6,500 \\
\hline $\mathrm{Ti}$ & $.3,980$ & 6,050 & 6,430 \\
\hline $\mathrm{Ba}$ & 1,684 & 2,590 & 93 \\
\hline $\mathrm{Sb}$ & $<1.9$ & 1,928 & 1,326 \\
\hline $\mathrm{La}$ & 2,700 & 2,910 & 3,490 \\
\hline $\mathrm{Ce}$ & 3,470 & 4,540 & 4,077 \\
\hline $\mathrm{S}$ & 3,440 & 1,060 & 1,100 \\
\hline
\end{tabular}

These analyses showed that the rare earths used in preparing the catalyst were a mixture of lanthanum and cerium. Antimony found in the spent catalyst was added during operation of the FCC unit in order to suppress the adverse effects of deposited nickel.

\subsection{HDS Catalyst}

Fresh and spent HDS catalyst samples were also analyzed by XRF. The results are shown in Table 2.2. The fresh catalyst consisted of sulfided nickel and molybdenum on an alumina support. The spent catalyst showed nearly $10 \%$ vanadium on the catalyst and a modest increase in nickel and sulfur on the catalyst as a result of operations. Heptane extraction of the catalyst was performed to remove soluble carbonaceous material because of the heterogeneous nature of the as-received sample. Following extraction, fine material that had adhered to the outside surfaces of the catalyst could be removed by sieving. A portion of the extracted and sieved hydrotreating catalyst was also calcined at $500^{\circ} \mathrm{C}$ in air to use in additional comparative experiments. 
Table 2.2. HDS Catalyst Sample Analyses

\begin{tabular}{|c|c|c|c|}
\hline $\begin{array}{c}\text { Solids } \\
\text { Composition, } \\
\text { ppm }\end{array}$ & Fresh Catalyst & $\begin{array}{c}\text { Spent Catalyst } \\
\text { (Heptane } \\
\text { Extracted) }\end{array}$ & $\begin{array}{c}\text { Spent Catalyst } \\
\text { (Calcined) }\end{array}$ \\
\hline $\mathrm{Al}$ & 593,000 & 295,000 & 411,200 \\
\hline $\mathrm{Si}$ & 13,690 & 10,400 & 18,100 \\
\hline $\mathrm{Ni}$ & 23,100 & 28,000 & 42,100 \\
\hline $\mathrm{Mo}$ & 38,900 & 19,700 & 22,500 \\
\hline $\mathrm{V}$ & 45 & 98,000 & 58,900 \\
\hline $\mathrm{Fe}$ & 170 & 2,310 & 4,670 \\
\hline $\mathrm{S}$ & 21,610 & 36,300 & 53,800 \\
\hline
\end{tabular}




\subsection{Electrochemical Dissolution for Processing Spent Catalyst}

A novel electrochemical oxidation process using cerium was investigated for processing spent FCC and HDS catalysts. While other metals such as nickel and silver are also suitable catalysts for the process, cerium was chosen because it would not create a toxic waste stream under Resource Conservation and Recovery Act (RCRA) regulations. As shown in Figure 3.1, spent catalyst is added to an acidic solution in the anode compartment of an electrochemical cell that contains small (catalytic) amounts of $\mathrm{Ce}^{+4}$ cations and spent catalyst. The $\mathrm{Ce}^{+4}$ ions migrate to the catalyst and react with the carbon and metal deposits on the catalyst, converting them to oxides and reducing the cerium to the +3 oxidation state. The $\mathrm{Ce}^{+3}$ cations are regenerated at the anode. The half-cell reaction for cerium is:

$$
\mathrm{Ce}^{3+} \rightleftharpoons \mathrm{Ce}^{+4}+\mathrm{e}-\mathrm{E}^{\circ}=-1.61 \text { volts }
$$

with the net anodic reactions

and

$$
\mathrm{C}_{\mathrm{x}} \mathrm{H}_{\mathrm{y}}+(2 \mathrm{x}) \mathrm{H}_{2} \mathrm{O} \rightarrow \mathrm{XCO}_{2}+(4 \mathrm{x}+\mathrm{y}) \mathrm{e}-+(4 \mathrm{x}+\mathrm{y}) \mathrm{H}^{+}
$$

metal sulfides + water $\rightarrow$ electrons + hydrogen ions + aqueous metal species + sulfate ions.

The anodic reactions for oxidation of metal sulfides in Equation (3.3) depend on the specific metal species present. Examples of anodic reactions for typical hydrotreating catalyst metals are:

$$
\begin{array}{ll}
\mathrm{NiS}+4 \mathrm{H}_{2} \mathrm{O} \rightarrow \mathrm{Ni}^{2+}+\mathrm{SO}_{4}{ }^{2-}+8 \mathrm{e}-+8 \mathrm{H}^{+} & \mathrm{E}^{\circ}=-0.31 \text { volts } \\
\mathrm{MoS}_{2}+12 \mathrm{H}_{2} \mathrm{O} \rightarrow \mathrm{MoO}_{4}{ }^{2-}+18 \mathrm{e}-+2 \mathrm{SO}_{4}{ }^{2-}+24 \mathrm{H}^{+} & \mathrm{E}^{\circ}=-0.43 \text { volts }
\end{array}
$$

In addition, water may dissociate to form oxygen at the anode:

$$
2 \mathrm{H}_{2} \mathrm{O} \rightarrow 4 \mathrm{H}^{+}+\mathrm{O}_{2}+4 \mathrm{e}-\quad \mathrm{E}^{\circ}=-1.23 \text { volts }
$$

The net anodic reactions are balanced by other reactions taking place at the cathode. Cathodic reactions are determined by the species present in the catholyte, cell potential, and mass transport characteristics in the cell.

Examples of cathode reactions expected using nitric acid as the catholyte are:

$$
\begin{array}{ll}
3 \mathrm{H}^{+}+\mathrm{NO}_{3}^{-}+2 \mathrm{e}-\rightarrow \mathrm{HNO}_{2}+\mathrm{H}_{2} \mathrm{O} & \mathrm{E}^{\circ}=0.94 \text { volts } \\
\mathrm{H}^{+}+\mathrm{HNO}_{2}^{-}+\mathrm{e}-\rightarrow \mathrm{NO}+2 \mathrm{H}_{2} \mathrm{O} & \mathrm{E}^{\circ}=1.00 \text { volts } \\
2 \mathrm{H}^{+}+2 \mathrm{e}-\rightarrow \mathrm{H}_{2} & \mathrm{E}^{\circ}=0.00 \text { volts }
\end{array}
$$

Reactions involving the cerium ions at the cathode are avoided by separating the anode and cathode with a semi-permeable membrane, and by maintaining an excess of hydrogen ions in solution in the anode compartment. 


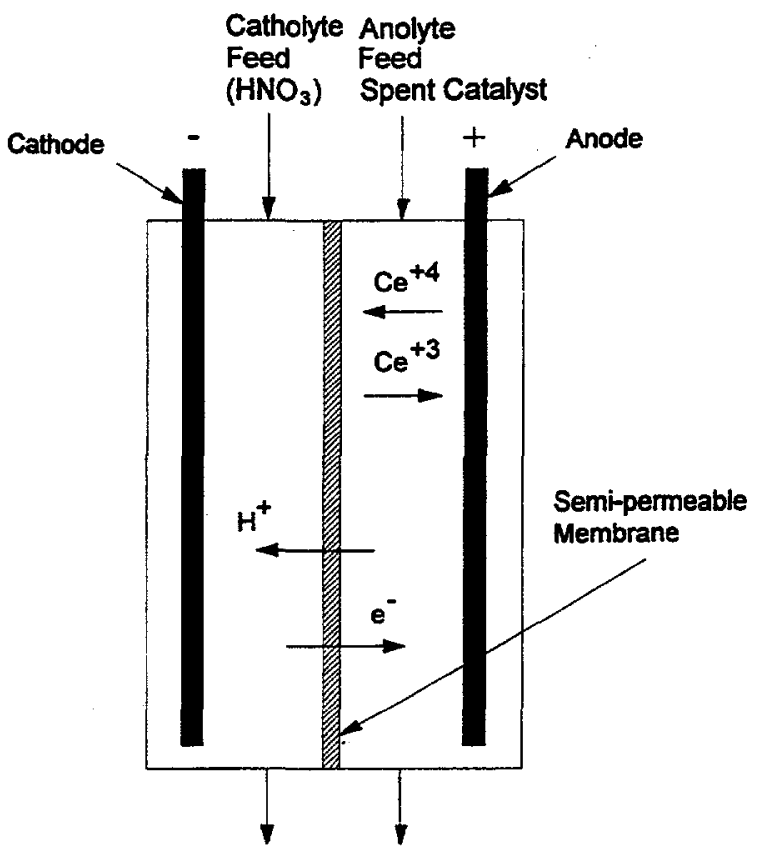

Figure 3.1. Electrochemical Cell Showing H+, e-, and Cerium Ion Transport

\subsection{Experiments and Results}

Two sets of experiments were conducted on FCC and HDS catalysts using the electrochemical oxidation process discussed above. The first set consisted of laboratory-scale batch dissolution experiments to investigate the effects of time, temperature, $\mathrm{Ce}^{+4}$ presence, and nitric acid concentration on catalyst dissolution and selectivity towards catalyst constituents and contaminants.

The second set of experiments was conducted to determine the conditions necessary to regenerate the $\mathrm{Ce}^{+3}$ to $\mathrm{Ce}^{+4}$ at the anode. Laboratory-scale experiments were also performed to investigate the effects of anolyte acidity, cell membrane composition, and nitrate ion concentration on current efficiency, cerium migration to the cathode, and cerium regeneration rate.

\subsubsection{Catalyst Dissolution}

Batch contact tests were run with nitric acid and/or ceric solutions and spent catalyst samples to determine the fate of the catalysts under various conditions. The ceric reagent was a commercially available $0.5 \mathrm{M}$ $\mathrm{Ce}^{+4}$ in $2 \mathrm{M}$ nitric acid solution. In a typical experiment, a $0.2-$ to 5.0 -g sample of spent catalyst was placed in a solution of $2 \mathrm{M}$ nitric acid, with and without $0.5 \mathrm{M}$ of $\mathrm{Ce}\left(\mathrm{NO}_{3}\right)_{4}$. The sample was then heated to a predetermined temperature and allowed to reflux at this temperature for a specified period of time. The treated sample was filtered and weighed to determine the amount of sample dissolution, and then analyzed by XRF to determine the composition of the remaining solid. The ceric ions were always present in considerable excess of the amount calculated as required to fully oxidize all components of the spent catalyst to their highest oxidation states. 
Table 3.1 summarizes the results of batch contacts of spent FCC catalyst in nitric acid with and without $\mathrm{Ce}^{+4}$. These results show that in the presence of $\mathrm{Ce}^{+4}$ at $70^{\circ} \mathrm{C}$, vanadium removal was significantly enhanced (as much as $81 \%$ removal). Nickel and iron also showed enhanced removal (as much as $45 \%$ and $69 \%$, respectively). However, most of the aluminum ( $81 \%$ ) was removed as well under these same conditions. Similarly, about $87 \%$ of the lanthanum was also removed. To determine if selectivity could be manipulated as a function of time, liquid samples were periodically withdrawn from a batch contact solution for analysis. Figure 3.2 shows the cumulative fraction of individual metal ions leached from the catalyst as a function of time. Note: the $y$-axis is based on comparing a questionable XRF measurement of vanadium in the starting material with inductively coupled plasma (ICP) analyses of liquid solutions. Therefore, calculated fractions greater than 1 are artifacts of analyses. However, vanadium removal is faster than the other components measured. These results suggest the possibility of using a cericmediated system combined with a short catalyst-contacting period to achieve selective removal of vanadium from the spent catalyst.

Table 3.1. Results of Batch Contact Experiments of $\mathrm{FCC}$ Catalysts Using $\mathrm{HNO}_{3}$ and $\mathrm{HNO}_{3} / \mathrm{Ce}^{+4}$ Solutions

\begin{tabular}{|c|c|c|c|c|c|c|c|}
\hline Reagent & Untreated & \begin{tabular}{|c|} 
Concentrated \\
HNO $_{3}$
\end{tabular} & $8 \mathrm{M} \mathrm{HNO}_{3}$ & \begin{tabular}{|c|}
$0.5 \mathrm{MCe} /$ \\
$2 \mathrm{M} \mathrm{HNO}_{3}{ }^{(2)}$
\end{tabular} & $\begin{array}{l}0.5 \mathrm{MCe} / \\
2 \mathrm{M} \mathrm{HNO}_{3}\end{array}$ & \begin{tabular}{|c|}
$0.5 \mathrm{M} \mathrm{Ce}^{(\mathrm{b}}$ \\
$2 \mathrm{M} \mathrm{HNO}_{3}{ }^{(\mathrm{b})}$
\end{tabular} & $\begin{array}{c}0.5 \mathrm{MCe} /^{2} \\
2 \mathrm{M} \mathrm{HNO}_{3}\end{array}$ \\
\hline $\begin{array}{l}\text { Initial Catalyst } \\
\text { Weight, } \mathrm{g}\end{array}$ & & 2.000 & 5.003 & 5.001 & 5.000 & 5.000 & 1.124 \\
\hline $\begin{array}{l}\text { Final Catalyst } \\
\text { Weight, } \mathrm{g}\end{array}$ & & 1.411 & NA & NA & 3.768 & 3.768 & 0.715 \\
\hline $\begin{array}{l}\text { Solution } \\
\text { Volume, } \mathrm{mL}\end{array}$ & & 100 & 400 & 375 & 400 & 400 & 200 \\
\hline Temperature & - & $70^{\circ} \mathrm{C}$ & $70^{\circ} \mathrm{C}$ & $70^{\circ} \mathrm{C}$ & $70^{\circ} \mathrm{C}$ & $70^{\circ} \mathrm{C}$ & $110^{\circ} \mathrm{C}$ \\
\hline Time & - & $20.5 \mathrm{hr}$ & $10.0 \mathrm{hr}$ & $10.0 \mathrm{hr}$ & $20.5 \mathrm{hr}$ & $20.5 \mathrm{hr}$ & $21.0 \mathrm{hr}$ \\
\hline Element & & & & $\mathrm{XRF}, \mathrm{ppm}$ & & & \\
\hline $\mathrm{Al}$ & 161,467 & 25,600 & 36,300 & 58,500 & 41,400 & 48,600 & 29,700 \\
\hline $\mathrm{Si}$ & 332,000 & 386,000 & 433,000 & 423,000 & 436,000 & 432,000 & 446,000 \\
\hline $\mathrm{S}$ & 1,100 & 1,820 & 830 & 950 & 1,016 & 790 & 660 \\
\hline $\mathrm{Ti}$ & 6,430 & 7,130 & 6,750 & 8,650 & 7,340 & 8,660 & 8,920 \\
\hline $\mathrm{V}$ & 1,455 & 316 & 661 & 343 & 371 & 166 & $<$ det. limit \\
\hline $\mathrm{Fe}$ & 6,500 & 1,146 & 3,260 & 3,770 & 2,640 & 2,770 & 1,110 \\
\hline $\mathrm{Ni}$ & 3,930 & 1,132 & 3,260 & 3,330 & 2,860 & 2,800 & 920 \\
\hline $\mathrm{Sb}$ & 1,329 & 3,210 & 2,210 & 2,050 & 2,320 & 1,886 & 1,311 \\
\hline $\mathrm{Ba}$ & 93 & 74 & 99 & 94 & 57 & 64 & 49 \\
\hline $\mathrm{La}$ & 3,490 & 766 & 866 & 682 & 603 & 480 & 378 \\
\hline $\mathrm{Ce}$ & 4,077 & 949 & 1,152 & 4,830 & 4,820 & 4,550 & 6,560 \\
\hline
\end{tabular}

(a) Solution was previously saturated in aluminum nitrate at room temperature.

(b) Duplicate analysis.

Chemical treatments of spent hydrotreating catalysts (Table 3.2) show essentially complete dissolution of the catalyst is achieved in $16 \mathrm{M}$ nitric acid and in $0.5 \mathrm{M} \mathrm{Ce}^{+4}$ in $2 \mathrm{M}$ nitric acid under 14 or more hours of reflux conditions. On the other hand, a significant portion of the catalyst was lost under all of the conditions tested except at ambient temperature. This indicates that a lower acid concentration, a temperature intermediate to ambient and $50^{\circ} \mathrm{C}$, and/or a shorter contact time are needed to improve 


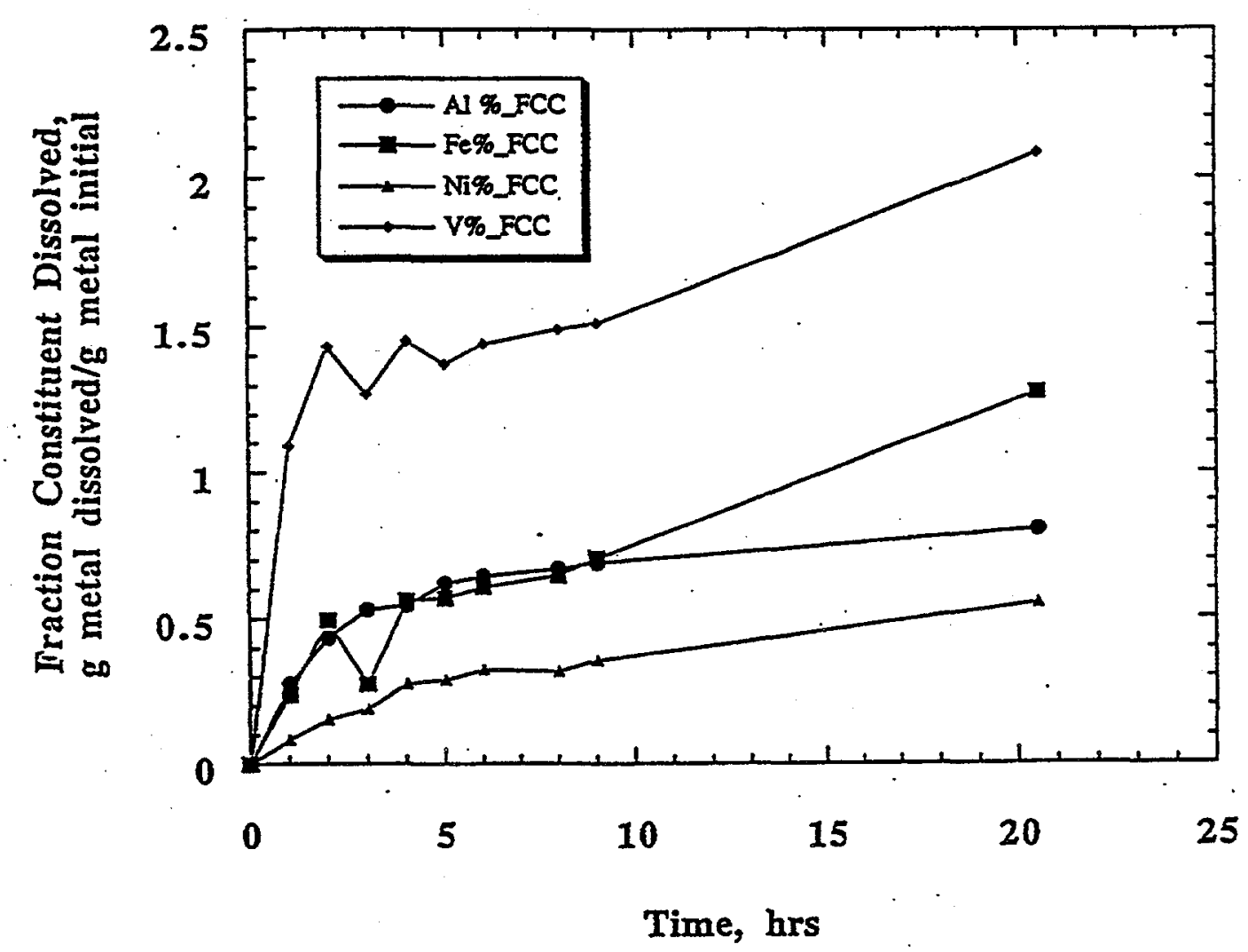

Figure 3.2. Batch Contact of Spent FCC Catalysts in Ceric Nitrate/Nitric Acid Solution

catalyst recovery to acceptable levels. However, the results at $50^{\circ} \mathrm{C}$ and $70^{\circ} \mathrm{C}$ also indicate a preferential dissolution of the other measured constituents relative to the aluminum dissolution in the catalyst. Consequently, milder conditions may achieve metals and sulfur removal without significant loss of the catalyst structure and properties (assuming that remaining levels of $\mathrm{Mo}$ and $\mathrm{Ni}$ can maintain catalyst activity).

\subsubsection{Electrochemical Ceric Ion Regeneration}

These experiments were performed using an H-type cell (Figure 3.3) to determine the feasibility of oxidizing $\mathrm{Ce}^{+3}$ in a low acidity supporting electrolyte. The main compartment of the $\mathrm{H}$-cell (about $150 \mathrm{~mL}$ ) was used for the anolyte. The anode, cathode, and reference electrodes were platinum. An ion selective membrane separated the anolyte and catholyte compartments. Both anionic and cationic membranes were used during the study.

UV/Vis spectroscopy was used to measure the ceric concentration because it is fast, simple to operate, and easily implemented for plant operation. However, for this application, nitrate/nitrite interference, sensitivity to $\mathrm{pH}$, and the stability of the ceric ion $\left(\mathrm{Ce}^{+4}\right)$ complicated the analysis. These problems were resolved by using sulfuric acid as a diluent and developing a calibration curve. The calibration curve was developed using potentiometric titration, a time-consuming method $(\sim 2 \mathrm{hr})$ but very accurate. For the potentiometric titration, the open circuit potential of the ceric solution is measured as ferrous ion is added. 
Table 3.2. XRF Results of Solids from Spent HDS Catalyst Treatments

\begin{tabular}{|c|c|c|c|c|c|c|c|}
\hline Reagent & Untreated & $\begin{array}{l}0.5 \mathrm{M} \mathrm{Ce}^{+4 /} \\
2 \mathrm{M} \mathrm{HNO}_{3}\end{array}$ & $\begin{array}{l}0.5 \mathrm{M} \mathrm{Ce}^{+4 /} \\
2 \mathrm{M} \mathrm{HNO}_{3}\end{array}$ & $\begin{array}{l}0.5 \mathrm{M} \mathrm{Ce}^{+4 /} / \\
2 \mathrm{M} \mathrm{HNO}_{3}\end{array}$ & $\begin{array}{l}0.5 \mathrm{MCe}^{+4 /} \\
2 \mathrm{M} \mathrm{HNO}_{3}\end{array}$ & $2 \mathrm{M} \mathrm{HNO}_{3}$ & $16 \mathrm{M} \mathrm{HNO}_{3}$ \\
\hline Catalyst Weight, $\mathrm{g}$ & & 0.2037 & 0.4025 & 0.4007 & 1.1471 & 0.8058 & 0.8057 \\
\hline Solution Volume, $\mathrm{mL}$ & & 40 & 100 & 100 & 200 & 200 & 200 \\
\hline Temperature & $\cdots$ & Ambient & $50^{\circ} \mathrm{C}$ & $70^{\circ} \mathrm{C}$ & $110^{\circ} \mathrm{C}$ & $103^{\circ} \mathrm{C}$ & $120^{\circ} \mathrm{C}$ \\
\hline Time & -- & $2+$ days & $28 \mathrm{hr}$ & $16 \mathrm{hr}$ & $14 \mathrm{hr}$ & $16.75 \mathrm{hr}$ & $16 \mathrm{hr}$ \\
\hline \% Solids Recovered & 100 & 100 & 37.4 & 16.3 & 0 & 15.2 & 0.9 \\
\hline $\begin{array}{l}\text { Composition of Recovered } \\
\text { Solids, } \mathrm{ppm}\end{array}$ & & (a) & & & (b) & (c) & (d) \\
\hline $\mathrm{Al}$ & 295,000 & $-\infty$ & 307,000 & 528,000 & -- & 34,800 & $-\infty$ \\
\hline Si & 10,400 & $m$ & 10,300 & 31,500 & $\cdots$ & 4,300 & -- \\
\hline V & 98,000 & -- & 2,920 & $<$ det. limit & - & 1,057 & -- \\
\hline $\mathrm{Ni}$ & 28,000 & - & 1,057 & 1,256 & - & 442 & - \\
\hline Mo & 19,700 & $\cdots$ & 2,810 & 618 & -- & 6,550 & - \\
\hline $\mathrm{Fe}$ & 2,310 & & 199 & 831 & & & \\
\hline $\mathrm{S}$ & 36,300 & - & 4,260 & 3,800 & -- & 24,800 & - \\
\hline
\end{tabular}

(a) Solids were not analyzed because no evidence of reaction had been observed.

(b) All the solids were dissolved.

(c) Remaining solids were black in this experiment. Remaining solids for other experiments were light-colored.

(d) Amount of solids remaining was too small to analyze by XRF. 


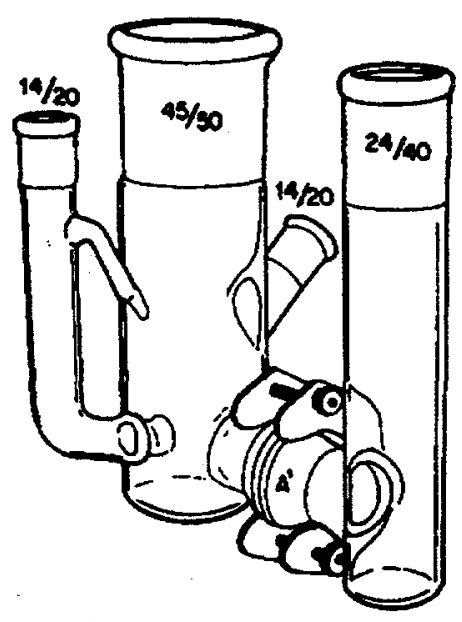

Figure 3.3. H-Type Cell Used for Tests on Electrochemical Ceric Ion Regeneration

An equivalence point is reached when the open circuit potential shifts from the cerium redox couple to the iron redox couple. At this point, the ceric concentration is equal to the amount of ferrous ion added to the solution. A sample titration curve is shown in Figure 3.4, and the resulting calibration curve is depicted in Figure 3.5. The absorbance increases linearly with ceric concentration, and the ceric ion is stable over a $48-\mathrm{hr}$ period.

In the first experiment, the $\mathrm{H}$-cell was set up with a cationic membrane and a solution of $\mathrm{Ce}\left(\mathrm{NO}_{3}\right)_{3}$ in the anolyte compartment. A potential of 2 volts was applied relative to the reference electrode voltage. No color change was observed in the anolyte and, thus, no oxidation of cerous to ceric ion occurred. (Dissolved $\mathrm{Ce}^{+4}$ is a bright orange color, while dissolved $\mathrm{Ce}^{+3}$ is colorless.) However, a white precipitate (cerous hydroxide) was observed in the catholyte compartment, which indicated that the cerous ion in the anolyte transported through the cationic membrane and combined with hydroxyl ions in the catholyte. The precipitation of cerous ion is an artifact of the H-cell geometry. For engineering applications, a flow-through cell would be used to eliminate this problem.

To reduce the cerous migration in the $\mathrm{H}$-cell, $5 \mathrm{~mL}$ of concentrated nitric acid were added to the anolyte compartment. The ionic mobility of $\mathrm{H}^{+}$is higher than that of $\mathrm{Ce}^{+3}$ and, therefore, $\mathrm{H}^{+}$will preferentially migrate through the membrane and allow the cerous ion to be oxidized at the anode. After the acid addition, the solution turned orange, indicating the generation of $\mathrm{Ce}^{+4}$ for both the anionic and cationic membrane experiments. In a separate test, a potassium/cerium nitrate solution was added to the anode side of the $\mathrm{H}$-cell, where the potassium:cerium ratio was 5:1. A short time after applying a potential to the cell, a solution color change again indicated generation of $\mathrm{Ce}^{+4}$ at the anode. These tests confirm that the more mobile cation, $\mathrm{K}^{+}$, can also be used to minimize $\mathrm{Ce}^{+3}$ migration to the cathode. The latter experiment also suggested that a fairly dilute solution of either cation is all that is needed to promote oxidation of the cerous cation.

Experiments were also conducted in a continuous flow microcell, with an electrode area of $10 \mathrm{~cm}^{2}$. In the first experiment, the microcell was used to regenerate ceric ion from a solution of cerous nitrate $(0.1 \mathrm{M})$ using a Nafion 454 cationic membrane. The microcell was operated in continuous mode at a constant current of $500 \mathrm{~mA}$ and a voltage of $2.5 \mathrm{~V}$. The anolyte solution color changed from clear to yellow/orange, indicating successful conversion of cerous to ceric ion. There did not appear to be any transport of the ceric ion across the membrane to the catholyte compartment. 


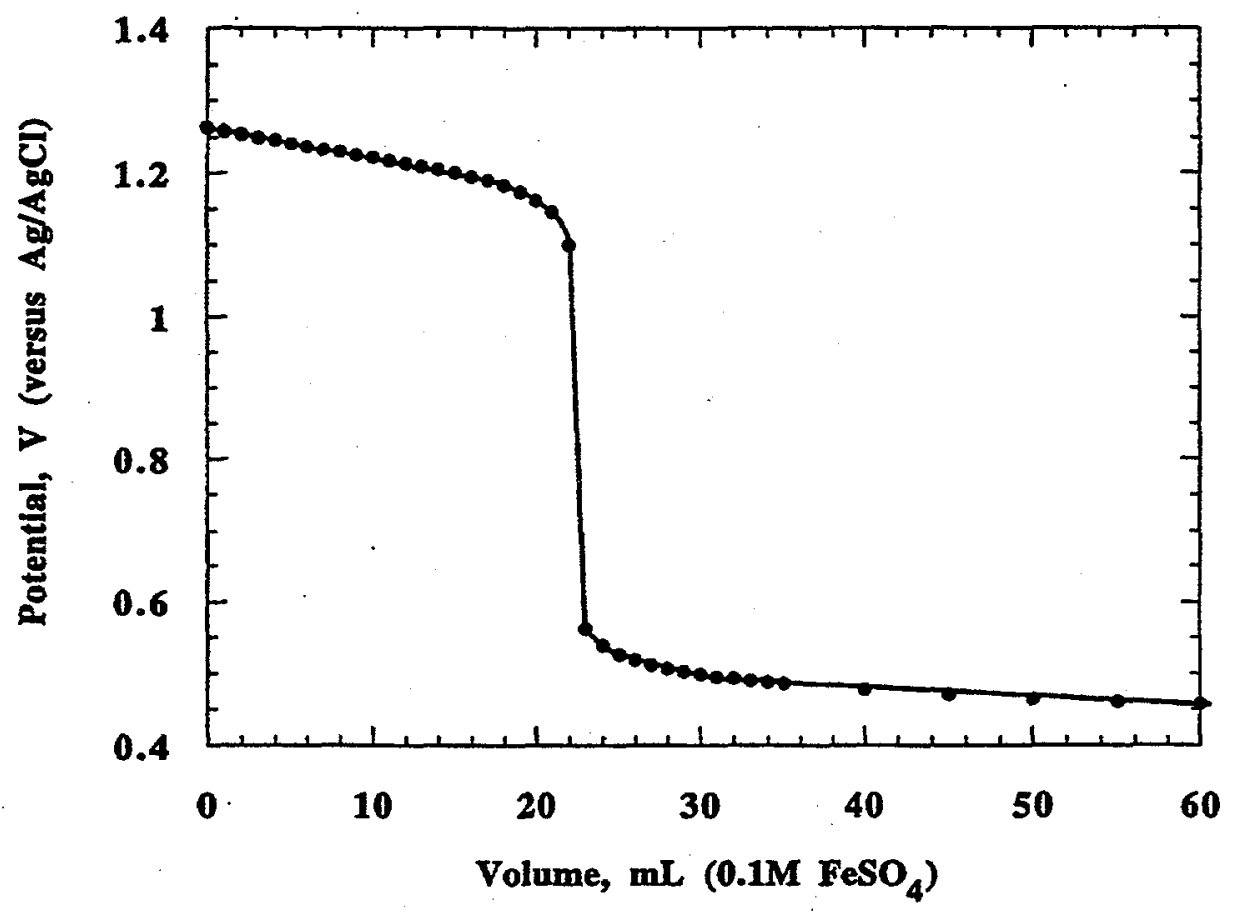

Figure 3.4. Potentiometric Titration Curve Showing Solution Potential as a Function of Ferrous Ion Concentration

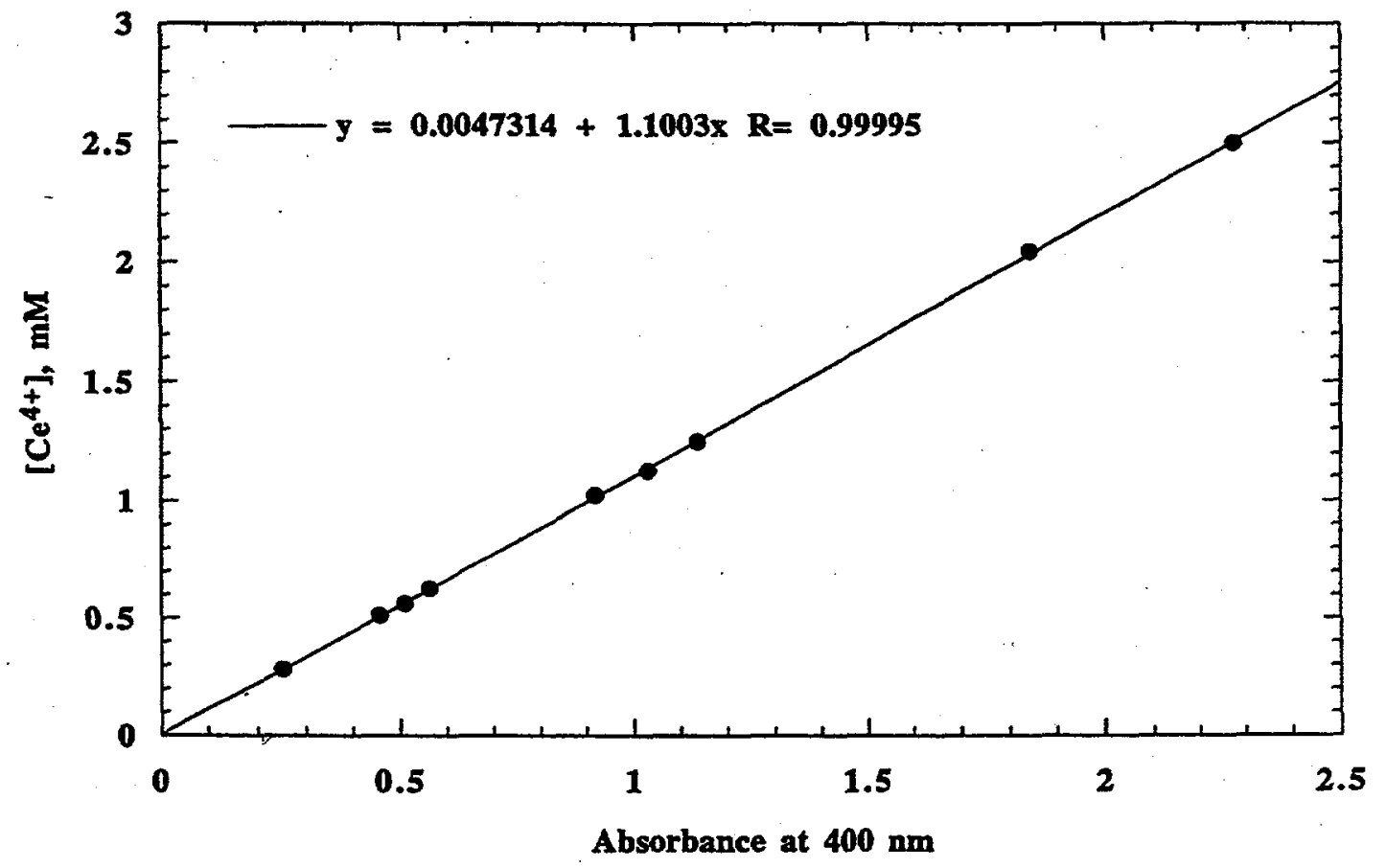

Figure 3.5 Ceric Ion Concentration as a Function of Absorbance at $400 \mathrm{~nm}$ 
Six additional experiments were run to evaluate the ability to convert cerous ion to ceric ion in nearneutral conditions $(\mathrm{pH}=5.06)$. All experiments were operated in a "once-through" configuration through the microcell at constant current. This operation was preferred over a batch process to avoid hydrogen ion buildup in the anolyte. The microcell was used with a platinized titanium anode, a nickel cathode, a Nafion 450 cationic separator, and a flow rate of $10 \mathrm{~mL} / \mathrm{min}$. The current was controlled, by a galvanostat, to values of $25,50,75,100,125$, and $270 \mathrm{~mA}$. The anolyte composition was $50 \mathrm{mM} \mathrm{Ce}\left(\mathrm{NO}_{3}\right)_{3}$ and $0.1 \mathrm{M} \mathrm{NaNO}_{3}$, and the catholyte was $50 \mathrm{mM} \mathrm{NaOH}$. Sodium was added to the anolyte to prevent the transport of cerous ion across the membrane into the catholyte compartment. The ceric concentration was measured using UV/VIS spectroscopy. Three different wavelengths $(350,370$, and $400 \mathrm{~nm})$ were used to measure the absorbance of the anolyte stream.

All of the product anolyte solutions were visibly colorless at the conclusion of each experiment. However, the UV/Vis measurements did show a trace increase in anolyte absorbance as the applied current was increased. The absorbances and associated concentrations are listed in Table 3.3. The conversion of cerous ion was very low $(0.06 \%)$ per pass.

The conversion of $\mathrm{Ce}^{+3}$ can be substantially increased if the process is operated in a batch mode, but to avoid significantly decreasing the $\mathrm{pH}$, it must operate without a membrane separator and include a component that will preferentially reduce over ceric ions. In this study, experiments were run in which cerous ions in $4 \mathrm{M} \mathrm{HNO}_{3}$ were oxidized to ceric ions in a flow cell without a separator. As a result, hydrogen ions were reduced more readily than ceric ions. The current efficiency in these experiments was also very low. For example, at the applied current of $270 \mathrm{~mA}$, the calculated current efficiency was less than $0.2 \%$, with most of the electrons producing oxygen from water instead of regenerating the cerous ion. Therefore, it was concluded that neutral conditions resulted in very low selectivity for the desired reaction. It was also noted in the earlier experiments that oxygen was being produced at the anode. However, the current efficiency was not determined for these earlier experiments at higher acidity.

Table 3.3. Ceric Regeneration at Close to Neutral Conditions

\begin{tabular}{|c|c|c|}
\hline $\begin{array}{c}\text { Applied Current, } \\
\mathbf{m A}\end{array}$ & $\begin{array}{c}\mathbf{I}_{\mathbf{o}}, \\
\text { at } \mathbf{4 0 0} \mathbf{~} \mathbf{m}\end{array}$ & $\begin{array}{c}\text { Ceric Concentration, } \\
\mathbf{~} \mathbf{M}\end{array}$ \\
\hline 0 & 0 & 0 \\
\hline 25 & 0 & 0 \\
\hline 50 & 0 & 0 \\
\hline 75 & 0.001 & 0.006 \\
\hline 100 & 0.01 & 0.015 \\
\hline 125 & 0.0215 & 0.026 \\
\hline 270 & 0.02 & 0.025 \\
\hline
\end{tabular}




\subsection{Conclusions}

The results of experiments to investigate the electrochemical dissolution concept showed that using $\mathrm{Ce}^{+4}$ as an oxidant was superior to using only nitric acid under comparable conditions, and that a $0.5 \mathrm{M} \mathrm{Ce}^{+2}$ solution in $2 \mathrm{M} \mathrm{HNO}_{3}$ at $110^{\circ} \mathrm{C}$ could completely dissolve spent $\mathrm{HDS}$ catalyst in $14 \mathrm{hr}$. Under milder conditions, it also appeared that vanadium, nickel, sulfur, molybdenum, and iron could be selectively removed from the aluminum support. The presence of $\mathrm{Ce}^{+2}$ in nitric acid was also found to significantly enhance the removal of vanadium from FCC catalyst. However, most of the aluminum was also removed under these conditions, and only modest removal of nickel was achieved. Silica in the FCC catalyst was relatively unaffected by this solution, and complete dissolution of the catalyst was not achieved.

Chemical regeneration of $\mathrm{Ce}^{+4}$ using an electrochemical cell was shown to be feasible under conditions of high concentrations of nitric acid as were used to maximize dissolution of the HDS and FCC catalysts. Under near-neutral conditions believed necessary to selectively remove metal impurities without damaging the catalyst support, it was concluded that the current efficiency was too low to be considered practical. 


\subsection{Other Chemical Dissolution Studies}

A limited number of experiments were conducted to investigate other chemical extraction methods to enhance metals removal while minimizing the dissolution of FCC and HDS catalyst supports. These experiments evaluated other oxidants and chelating reagents than were tested in the cerium experiments discussed in Section 3.0.

\subsection{Experiments and Results}

\subsubsection{Batch Contact Tests with FCC Catalyst}

Batch contact tests using FCC catalyst and chelating reagents were conducted using $2.0 \mathrm{~g}$ of catalyst in $200 \mathrm{~mL}$ of solution and heating to $100^{\circ} \mathrm{C}$ for a predetermined period (16 to $22 \mathrm{hr}$ ). An experiment using $\mathrm{FCC}$ catalyst in $\mathrm{H}_{2} \mathrm{O}_{2}$ consisted of three extraction sequences. Each extraction sequence involved adding $20 \mathrm{~mL}$ of $30 \% \mathrm{H}_{2} \mathrm{O}_{2}$, reacting for a short period of time ( $\left.40 \mathrm{~min}\right)$, followed by rinsing the solids and decanting the rinse solution. The catalyst/solution was warmed slightly during the second and third sequences. The treated samples were filtered, dried, and weighed to determine the amount of sample dissolution, and analyzed using XRF to determine the composition of the remaining solid.

Table 4.1 shows the results of the experiments using the FCC catalyst. The most promising experiment was the one using $\mathrm{H}_{2} \mathrm{O}_{2}$ because it did not cause dealumination of the zeolite catalyst or removal of lanthanum, and achieved a modest $22 \%$ vanadium removal; however, nickel was not removed. Qualitatively, the $\mathrm{H}_{2} \mathrm{O}_{2}$ appeared to remove coke that was in the spent catalyst. The reactions with maleic acid and $\mathrm{Na}_{2}$ EDTA caused significant dealumination of the catalyst. The three experiments using ammoniacal solutions did not remove any nickel, although the $\mathrm{NH}_{4} \mathrm{Cl}$ and ammonium citrate solutions achieved a modest removal of vanadium ( $19 \%$ and $43 \%$, respectively), and iron (12\% and $37 \%$, respectively). However, these latter two solutions also resulted in modest dealumination of the catalyst and removal of the rare earths (cerium and lanthanum).

\subsubsection{Batch Contact Test with HDS Catalyst}

One set of batch contact tests was conducted using $2.0 \mathrm{~g}$ of HDS catalyst with the desired solution. The HDS catalyst used in these tests was the same as was used in the previous tests (heptane extracted), except that it was calcined in air at $500^{\circ} \mathrm{C}$ for $14 \mathrm{hr}$ to burn off any remaining coke. In two experiments using citric acid, the HDS catalyst was reacted in two steps using $100 \mathrm{~mL}$ of solution followed by rinsing and decanting. In an experiment using $\mathrm{H}_{2} \mathrm{O}_{2}$, the catalyst was reacted in four steps using $25 \mathrm{~mL}$ of solution followed by rinsing and decanting. The treated samples were then filtered, dried, and weighed to determine the amount of sample dissolution, and analyzed using XRF to determine the composition of the remaining solid.

Table 4.2 shows the results of experiments with the calcined, heptane-extracted spent HDS catalyst. Extraction with $\mathrm{H}_{2} \mathrm{O}_{2}$ resulted in significant removal of $\mathrm{Fe}(71 \%), \mathrm{V}(83 \%), \mathrm{Ni}(91 \%), \mathrm{S}(95 \%)$, and Mo $(86 \%)$ without a significant change in the $\mathrm{Al} / \mathrm{Si}$ ratio. The total weight loss of $53.5 \%$, which is greater than would be expected by the removal of only the contaminant constituents and molybdenum, suggests that at least some $\mathrm{Al}$ and $\mathrm{Si}$ was removed during extraction. Similar, but more modest, results were obtained with the citric acid extraction at $90^{\circ} \mathrm{C}$. 
Table 4.1. Spent FCC Catalyst Treatment

\begin{tabular}{|c|c|c|c|c|c|c|c|}
\hline Reagent & Untreated & $30 \% \mathrm{H}_{2} \mathrm{O}_{2}$ & $\begin{array}{l}1 \text { M Maleic } \\
\text { Acid }\end{array}$ & $\begin{array}{c}0.5 \mathrm{M} \\
\mathrm{Na}_{2} \text { EDTA }\end{array}$ & $\begin{array}{l}0.5 \mathrm{M} \mathrm{NH}_{4} \mathrm{Cl} / \\
0.5 \mathrm{M} \mathrm{NH}_{4} \mathrm{OH}\end{array}$ & $1 \mathrm{M} \mathrm{NH}_{4} \mathrm{Cl}$ & $\begin{array}{c}\mathbf{M} \\
\begin{array}{c}\text { Ammonium } \\
\text { Citrate }\end{array}\end{array}$ \\
\hline Temperature & & $80^{\circ} \mathrm{C}$ & $100^{\circ} \mathrm{C}$ (reflux) & $100^{\circ} \mathrm{C}$ (reflux) & $100^{\circ} \mathrm{C}$ (reflux) & $100^{\circ} \mathrm{C}$ (reflux) & $100^{\circ} \mathrm{C}$ (reflux) \\
\hline $\begin{array}{l}\text { Catalyst } \\
\text { Weight, } \mathrm{g}\end{array}$ & & 5.000 & 2.000 & 2.000 & 2.000 & 2.000 & 2.000 \\
\hline $\begin{array}{l}\text { Solution } \\
\text { Volume, } \mathrm{mL}\end{array}$ & -- & 60 & 200 & 200 & 250 & 200 & 200 \\
\hline Time & - & $2.0 \mathrm{hr}$ & $22.0 \mathrm{hr}$ & $20.0 \mathrm{hr}$ & $22.0 \mathrm{hr}$ & $16.0 \mathrm{hr}$ & $18.0 \mathrm{hr}$ \\
\hline $\begin{array}{l}\text { \% Solids } \\
\text { Recovered }\end{array}$ & & 99.6 & 54.7 & 71.2 & 95.9 & 97.9 & 83.8 \\
\hline Element & \multicolumn{7}{|c|}{$\mathrm{XRF}, \mathrm{ppm}$} \\
\hline $\mathrm{Al}$ & 161,467 & 164,400 & 38,300 & 64,200 & 166,600 & 134,000 & 127,800 \\
\hline $\mathrm{Si}$ & 332,000 & 307,200 & 416,000 & 399,000 & 314,000 & 285,000 & 329,000 \\
\hline$S$ & 1,100 & 990 & 963 & 906 & 770 & $<$ det. limit & 860 \\
\hline $\mathrm{Ti}$ & 6,430 & 6,040 & 7,680 & 7,580 & 6,320 & 5,590 & 7,300 \\
\hline $\mathrm{V}$ & 1,455 & 1,135 & 686 & 754 & 1,429 & 1,174 & 993 \\
\hline $\mathrm{Fe}$ & 6,500 & 6,720 & 2,800 & 3,460 & 6,170 & 5,710 & 4,900 \\
\hline $\mathrm{Ni}$ & 3,930 & 4,330 & 2,990 & 3,620 & 3,830 & 3,930 & 3,780 \\
\hline$\overline{\mathrm{Sb}}$ & 1,329 & 1,210 & 1,872 & 1,872 & 1,251 & 1,670 & 953 \\
\hline$\overline{\mathrm{Ba}}$ & 93 & 145 & 69 & 115 & 75 & 106 & 88 \\
\hline $\mathrm{La}$ & 3,490 & 3,550 & 811 & 1,436 & 2,860 & 2,580 & 1,596 \\
\hline $\mathrm{Ce}$ & 4,077 & 4,810 & 1,047 & 1,850 & 3,640 & 3,410 & 2,030 \\
\hline
\end{tabular}


Table 4.2. Dissolution Tests for HDS Catalyst

\begin{tabular}{|c|c|c|c|c|}
\hline Reagent & $\begin{array}{c}\text { Untreated, } \\
\text { Heptane } \\
\text { Extracted and } \\
\text { Calcined }\end{array}$ & $30 \% \mathrm{H}_{2} \mathrm{O}_{2}$ & $\begin{array}{l}0.1 \text { M Citric } \\
\text { Acid }\end{array}$ & $\begin{array}{c}0.1 \text { M Citric } \\
\text { Acid }\end{array}$ \\
\hline Catalyst Weight, $\mathrm{g}$ & & 2.000 & 2.000 & 2.000 \\
\hline Solution Volume, $\mathrm{mL}$ & & $100^{(2)}$ & $200^{(6)}$ & $200^{(6)}$ \\
\hline Temperature & - & Room Temp. & Room Temp. & $90^{\circ} \mathrm{C}$ \\
\hline Time & -- & $2 \mathrm{hr}$ & $2 \mathrm{hr}$ & $2 \mathrm{hr}$ \\
\hline$\%$ Solids Recovered & 100 & 53.5 & 72.5 & 48.0 \\
\hline \multicolumn{5}{|c|}{$\begin{array}{l}\text { Composition of Recovered } \\
\text { Solids (XRF), ppm }\end{array}$} \\
\hline $\mathrm{Al}$ & 411,200 & 403,600 & 366,500 & 418,500 \\
\hline $\mathrm{Si}$ & 18,100 & 14,580 & 15,620 & 14,930 \\
\hline $\mathrm{V}$ & 58,900 & 19,150 & 108,300 & 29,350 \\
\hline $\mathrm{Ni}$ & 42,000 & 6,600 & 44,800 & 13,240 \\
\hline Mo & 22,500 & 5,880 & 21,100 & 11,920 \\
\hline $\mathrm{Fe}$ & 4,670 & 2,530 & 3,880 & 904 \\
\hline $\bar{S}$ & 53,800 & 5,990 & 21,360 & 4,110 \\
\hline
\end{tabular}

(a) Added in 25-mL increments with rinsing and decanting between steps.

(b) Added in $100-\mathrm{mL}$ increments with rinsing and decanting between steps.

A second set of batch contact tests was conducted with $0.2 \mathrm{~g}$ of the HDS catalyst that was heptane extracted, but not calcined, to investigate alkaline leaching conditions using ammonia and $\mathrm{H}_{2} \mathrm{O}_{2}$ mixtures. All extractions were performed by adding $10 \mathrm{~mL}$ of extractant to the catalyst and allowing the mixture to stand without mixing for the predetermined length of time. The total extraction time for each sample was approximately $4 \mathrm{hr}$. However, the first two tests involved two extractions. In the first test, the first leach solution contained only $1 \mathrm{M} \mathrm{NH}_{3} \mathrm{OH}$, and leaching took place over $3 \mathrm{hr}$. The solution was decanted and replaced with a second leach solution containing $0.1 \mathrm{M} \mathrm{NH}_{3} \mathrm{OH}$ and $0.1 \mathrm{M} \mathrm{H}_{2} \mathrm{O}_{2}$ and allowed to stand for over $1 \mathrm{hr}$. In the second test, the first leach solution contained both reagents ( $1 \mathrm{M} \mathrm{NH}_{3} \mathrm{OH}$ and $0.1 \mathrm{M} \mathrm{H}_{2} \mathrm{O}_{2}$ ) and took place over $1 \mathrm{hr}$, at which time bubble generation appeared to stop. The solution was decanted and replaced with a second identical leach solution that took place over $3 \mathrm{hr}$. The remaining three tests involved single 4 -hr extractions using less concentrated leachate solutions. Leachate solutions were analyzed using ICP-atomic emission spectroscopy (AES). Extraction efficiencies were calculated based on the recovered leachate volume and the heptane-extracted analysis for the spent catalyst from Table 2.2. The test conditions and results for these tests are shown in Table 4.3.

It is apparent from the first set of results in Table 4.3 that the samples may be exhibiting heterogeneous effects due to the small sample size, as suggested by the $134 \%$ recovery of molybdenum, particularly with respect to the untreated hexane-extracted sample used as the baseline for calculating percent extracted (Table 2.2). Consequently, the quantitative results for these tests need to be interpreted with caution.

All of the samples were selectively leached for vanadium, nickel, molybdenum, and sulfur over iron and aluminum. It was not possible to remove vanadium without simultaneously removing molybdenum. Furthermore, molybdenum appeared to be more readily extracted than vanadium in all but one of the tests. 
Table 4.3. Alkaline Leaching of HDS Catalyst

\begin{tabular}{|c|c|c|c|c|c|}
\hline $\begin{array}{l}\text { First Leachate } \\
\text { Composition }\end{array}$ & $1.0 \mathrm{M} \mathrm{NH}_{3} \mathrm{OH}$ & $\begin{array}{c}1.0 \mathrm{M} \mathrm{NH}_{3} \mathrm{OH} \\
1.0 \mathrm{M} \mathrm{H}_{2} \mathrm{O}_{2}\end{array}$ & {$\left[\begin{array}{c}0.2 \mathrm{M} \mathrm{NH}_{3} \mathrm{OH} \\
0.1 \mathrm{M} \mathrm{H}_{2} \mathrm{O}_{2}\end{array}\right.$} & $\begin{array}{c}0.2 \mathrm{M} \mathrm{NH}_{3} \mathrm{OH} \\
1.0 \mathrm{M} \mathrm{H}_{2} \mathrm{O}_{2}\end{array}$ & $\begin{array}{c}1.0 \mathrm{M} \mathrm{NH}_{3} \mathrm{Cl} \text {, } \\
0.1 \mathrm{M} \mathrm{H}_{2} \mathrm{O}_{2}\end{array}$ \\
\hline $\begin{array}{l}\text { Second Leachate } \\
\text { Composition }\end{array}$ & $\begin{array}{c}1.0 \mathrm{M} \mathrm{NH}_{3} \mathrm{OH} \\
1.0 \mathrm{M} \mathrm{H}_{2} \mathrm{O}_{2}\end{array}$ & $\begin{array}{c}1.0 \mathrm{M} \mathrm{NH}_{3} \mathrm{OH} \\
1.0 \mathrm{M} \mathrm{H}_{2} \mathrm{O}_{2}\end{array}$ & NA & NA & NA \\
\hline Catalyst Weight, $\mathrm{g}$ & 0.201 & 0.198 & 0.208 & 0.2025 & 0.1986 \\
\hline $\begin{array}{l}\text { First Extraction Liquid } \\
\text { Sample Volume, mL } \\
\end{array}$ & 9.4 & 9.5 & 9.6 & 9.3 & 9.9 \\
\hline $\begin{array}{l}\text { Second Extraction liquid } \\
\text { Sample Volume, mL } \\
\end{array}$ & 9.8 & 9.4 & NA & NA & NA \\
\hline First Extraction & \multicolumn{5}{|c|}{$\frac{1}{\text { Percent Extracted }}$} \\
\hline $\mathrm{V}$ & $26.7 \%$ & $52.6 \%$ & $13.4 \%$ & $45.2 \%$ & $13.8 \%$ \\
\hline$\overline{\mathrm{Ni}}$ & $34.5 \%$ & $28.9 \%$ & $15.3 \%$ & $20.4 \%$ & $52.7 \%$ \\
\hline Mo & $62.9 \%$ & $21.1 \%$ & $43.7 \%$ & $71.3 \%$ & $15.4 \%$ \\
\hline $\mathrm{S}$ & $41.35 \%$ & $20.18 \%$ & $15.41 \%$ & $20.28 \%$ & $14.01 \%$ \\
\hline Second Extraction & \multicolumn{5}{|c|}{ Percent Extracted } \\
\hline $\mathrm{V}$ & $51.9 \%$ & $33.9 \%$ & \begin{tabular}{|l|}
$\mathrm{NA}$ \\
\end{tabular} & $\overline{\mathrm{NA}}$ & $\overline{\mathrm{NA}}$ \\
\hline $\mathrm{Ni}$ & $44.5 \%$ & $19.7 \%$ & $\overline{\mathrm{NA}}$ & NA & NA \\
\hline Mo & $71.5 \%$ & $15.8 \%$ & NA & NA & $\overline{\mathrm{NA}}$ \\
\hline $\mathrm{S}$ & $48.89 \%$ & $14.80 \%$ & \begin{tabular}{|l|}
$\mathrm{NA}$ \\
\end{tabular} & NA & NA \\
\hline Extraction Total & \multicolumn{5}{|c|}{ Percent Extracted } \\
\hline $\mathrm{V}$ & $78.6 \%$ & $86.5 \%$ & \begin{tabular}{l|l}
$13.4 \%$ \\
\end{tabular} & $45.2 \%$ & $13.8 \%$ \\
\hline $\mathrm{Ni}$ & $79.0 \%$ & $48.6 \%$ & $15.3 \%$ & $20.4 \%$ & $52.7 \%$ \\
\hline Mo & $134.3 \%$ & $37.0 \%$ & $43.7 \%$ & $71.3 \%$ & $15.4 \%$ \\
\hline $\mathrm{S}$ & $90.25 \%$ & $34.98 \%$ & $15.41 \%$ & $20.28 \%$ & $14.01 \%$ \\
\hline$\overline{\mathrm{Fe}}$ & $0.32 \%$ & $0.21 \%$ & $0.72 \%$ & $0.80 \%$ & $4.38 \%$ \\
\hline$\overline{\mathrm{Al}}$ & $1.10 \%$ & $2.78 \%$ & $0.20 \%$ & $0.81 \%$ & $1.84 \%$ \\
\hline
\end{tabular}

The vanadium appeared to be better extracted in the solutions with a higher $\mathrm{H}_{2} \mathrm{O}_{2}$ concentration in combination with higher ammonium hydroxide. The higher $\mathrm{H}_{2} \mathrm{O}_{2}$ may be beneficial by oxidizing the vanadium to a higher, more soluble form. The lower results using $\mathrm{NH}_{3} \mathrm{Cl}$ instead of $\mathrm{NH}_{3} \mathrm{OH}$ suggest the higher $\mathrm{pH}$ achieved using the hydroxide improves vanadium extraction.

The higher nickel extractions occurred with the solutions having the highest ammonium concentration either as hydroxide or as chloride. The modest extraction of nickel using only $\mathrm{NH}_{3} \mathrm{OH}$ would be consistent with ammonia complex formation with reduced nickel on the catalyst as opposed to nickel sulfide. The addition of $\mathrm{H}_{2} \mathrm{O}_{2}$ along with the higher ammonium concentrations appears to further improve nickel extraction and would be consistent with oxidation of the sulfide.

The best overall extraction occurred when the catalyst was first extracted with $1.0 \mathrm{M} \mathrm{NH}_{3} \mathrm{OH}$ prior to extracting with an $\mathrm{NH}_{3} \mathrm{OH} / \mathrm{H}_{2} \mathrm{O}_{2}$ mixture. There also appears to be an advantage to leaching first with $\mathrm{NH}_{3} \mathrm{OH}$ before leaching with the mixture, which is indicated by comparing the first and second leaches of the first two experiments shown in Table 4.3. The first experiment actually had a higher recovery of each constituent in the second leach, whereas the second experiment showed a reduced recovery as might be expected with a second identical leach. 


\subsection{Conclusions}

The results of the experiments to selectively leach metals from FCC catalyst showed that solutions containing maleic acid, $\mathrm{Na}_{2} \mathrm{EDTA}, \mathrm{NH}_{4} \mathrm{Cl}$, or ammonium citrate resulted in significant dealumination of the catalyst, whereas solutions containing $\mathrm{H}_{2} \mathrm{O}_{2}$ or a mixture of $\mathrm{NH}_{4} \mathrm{Cl}$ and $\mathrm{NH}_{4} \mathrm{OH}$ did not. However, the $\mathrm{NH}_{4} \mathrm{OH}$ did cause significant removal of lanthanum, which would make it unsuitable for regenerating the catalyst. On the other hand, the $\mathrm{H}_{2} \mathrm{O}_{2}$ only achieved a modest removal of vanadium from the catalyst and did not appear to remove any of the other metals.

The results of experiments to selectively leach metals from $\mathrm{HDS}$ catalyst showed that a $30 \% \mathrm{H}_{2} \mathrm{O}_{2}$ solution would selectively leach nickel, vanadium, iron, molybdenum, and sulfur, but at high concentrations $\left(30 \% \mathrm{H}_{2} \mathrm{O}_{2}\right)$ the structural integrity of the catalyst was lost. Leaching with citric acid at elevated temperature $\left(90^{\circ} \mathrm{C}\right)$ also resulted in selective removal of these metals, but it also appeared to result in a loss of the alumina catalyst support. Extraction of the catalyst with $1.0 \mathrm{M} \mathrm{NH}_{4} \mathrm{OH}$ followed by a second extraction with a mixture of $1.0 \mathrm{M} \mathrm{H}_{2} \mathrm{O}_{2}$ and $1.0 \mathrm{M} \mathrm{NH} 4 \mathrm{OH}$ appeared to provide the best overall removal of vanadium, nickel, and molybdenum from the catalyst. More importantly, this sequence of extractions did not appear to cause a loss of aluminum from the catalyst support. 


\subsection{Hydrothermal Treatement of Spent FCC Catalysts}

Hydrothermal processing uses aqueous solutions at temperatures at or above the normal boiling point to accelerate reaction rates, along with elevated pressure to maintain a liquid phase in the reactor. Hydrothermal processing of FCC catalyst was tested because it could maintain a lower acidity of the solution to minimize dissolution of the catalyst support. Hydrothermal processing with and without the use of oxidants at relatively modest concentrations was also investigated.

\subsection{Experiments and Results}

An apparatus for hydrothermal extraction was assembled using a small autoclave, shown schematically in Figure 5.1. Test tubes used to contain the catalyst and extraction solution were cleaned before the experiments to remove any contaminants. The cleaning procedure included soaking the test tubes in a concentrated nitric acid solution at elevated temperature to thoroughly leach aluminum from the tubes. Approximately $0.5 \mathrm{~g}$ of catalyst along with about $5 \mathrm{~mL}$ of extraction solution and a PTFE-coated stir bar were placed in a test tube. A PTFE cap was fabricated and placed on the test tube, and the assembly was placed in an autoclave. The space between the outer wall of the test tube and the inner wall of the autoclave was filled with distilled, deionized water. A polyimide-coated fused silica capillary tube was fed through the autoclave pressure fitting, and inserted into the tube through the PTFE cap. The distal end of the capillary tube had previously been sealed with a high-temperature flame. For experiments at higher temperatures $\left(>200^{\circ} \mathrm{C}\right)$, the polyimide coating was removed from the fused silica capillary over the region exposed to hydrothermal conditions to prevent potential interfering contamination in the offline effluent assay.

The autoclave was sealed and connected to a pressure system, which included a rupture disk and a pressure transducer. The autoclave was then heated to the predetermined temperature while mixing the catalyst reagent solution via a magnetically coupled stirrer. After a specified time at temperature, stirring was discontinued and the flame-sealed end of the capillary tube was broken to allow the extraction effluent to be collected at the extraction temperature. The effluent was collected in a vial containing about $1 \mathrm{~mL}$ of dilute $(1 \mathrm{M})$ nitric acid. The effluents were later assayed for $\mathrm{V}, \mathrm{Ni}, \mathrm{Al}, \mathrm{La}$, $\mathrm{Sb}, \mathrm{Rb}$, and $\mathrm{Ce}$ using ICP-mass spectroscopy (MS). The data analysis included correcting the concentrations determined for the various species for dilution due to the nitric acid collecting solution. The concentrations were then normalized to the initial $5-\mathrm{mL}$ extractant volume because some of the extractant solution was evaporated during collection, particularly in experiments at the higher temperatures. After cooling to a temperature below $100^{\circ} \mathrm{C}$, the autoclave was opened and the tube containing the catalyst sample was removed.

Preparation of the catalyst for each test included washing with distilled, deionized water followed by decanting to remove "fines." This procedure was carried out to minimize the possibility of plugging the capillary. The catalyst was also "spiked" with rubidium (from $\mathrm{RbNO}_{3}$ ) as an internal standard for the fractional factorial experiments.

The range of the variables used in the first set of experiments is shown in Table 5.1. Time, temperature, hydrogen peroxide concentration, nitric acid concentration, and cerium IV concentration were the independent variables. The source of cerium IV was a $\mathrm{Ce}^{+4} / \mathrm{HNO}_{3}$ mixture $\left[0.5 \mathrm{M} \mathrm{Ce}^{+4}\right.$ in $2 \mathrm{M} \mathrm{HNO}_{3}$ ]. The nitric acid concentration shown in the table includes the nitric acid added with the cerium. Cerium IV and hydrogen peroxide were not used together in the extraction solutions because cerium IV oxidizes hydrogen peroxide to water and oxygen. 


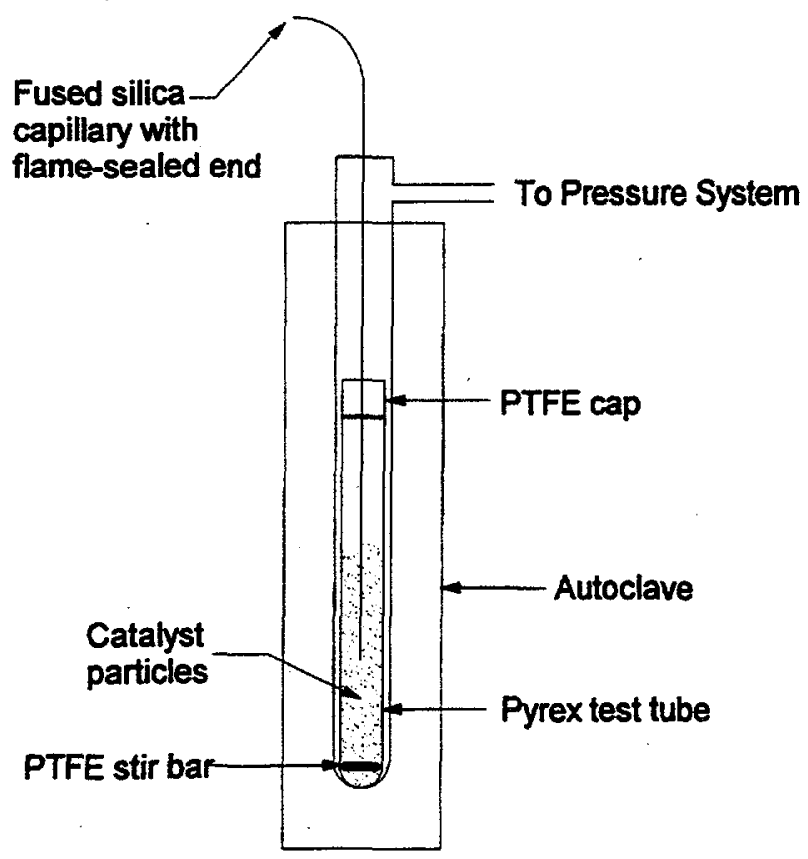

Figure 5.1. Diagram of Apparatus Used for Hydrothermal Extractions

Table 5.1. Summary of the Experimental Parameters and Results for the First Set of Experiments

\begin{tabular}{|c|c|c|c|c|c|c|c|c|}
\hline \multirow{2}{*}{ Experiment } & \multirow{2}{*}{ Time, $\min$} & \multirow{2}{*}{ Temp., $^{\circ} \mathbf{C}$} & $\mathbf{H}_{\mathbf{2}} \mathbf{O}_{\mathbf{2}} \mathbf{M}$ & \multirow{2}{*}{$\mathrm{Ce}^{+4} \mathbf{M}$} & \multicolumn{2}{|c|}{$\mathrm{HNO}_{\mathbf{3}} \mathbf{M}$} & \multicolumn{3}{|c|}{ Wt \% Extracted from Catalyst } \\
\hline 1 & 30 & 100 & 0.00 & 0.00 & 0.00 & $\mathbf{A l}$ & $\mathbf{V}$ & $\mathbf{N i}$ \\
\hline 2 & 90 & 175 & 0.00 & 0.00 & 0.00 & 0.02 & 5.51 & 0.09 \\
\hline 3 & 60 & 137.5 & 0.00 & 0.01 & 0.07 & 3.99 & 9.44 & 2.95 \\
\hline 4 & 90 & 100 & 0.00 & 0.00 & 0.10 & 7.82 & 8.96 & 3.38 \\
\hline 5 & 30 & 175 & 0.00 & 0.00 & 0.10 & 3.59 & 6.33 & 4.62 \\
\hline 6 & 30 & 100 & 5.26 & 0.00 & 0.10 & 6.27 & 8.36 & 2.98 \\
\hline 7 & 90 & 100 & 0.00 & 0.10 & 0.04 & 1.64 & 2.43 & 1.68 \\
\hline 8 & 30 & 175 & 0.00 & 0.10 & 0.04 & 1.55 & 8.69 & 3.80 \\
\hline 9 & 30 & 100 & 0.00 & 0.10 & 0.14 & 12.23 & 6.78 & 3.67 \\
\hline 10 & 90 & 100 & 5.26 & 0.00 & 0.00 & 0.08 & 8.67 & 0.49 \\
\hline 11 & 60 & 137.5 & 2.60 & 0.00 & 0.05 & 0.02 & 2.81 & 0.84 \\
\hline 12 & 90 & 100 & 0.00 & 0.10 & 0.14 & 9.26 & 7.95 & 3.56 \\
\hline 13 & 30 & 175 & 5.26 & 0.00 & 0.00 & 0.01 & 2.03 & 0.74 \\
\hline
\end{tabular}

A yellow, gelatinous precipitate was observed above the extracted catalyst in the experiments where cerium IV was included in the extraction solution. The precipitate that forms when $\mathrm{Ce}^{+4}$ is added is probably $\mathrm{CeO}_{2} \cdot \mathrm{nH}_{2} \mathrm{O}$, the product of a hydrolysis reaction. When the stock solution containing $\mathrm{Ce}^{+4}$ is introduced into the extraction solution, the resulting increase in $\mathrm{pH}$ due to dilution $(\sim-0.3$ to $\sim 1.3)$ and the accompanying increase in hydroxide ion concentration make the hydrolysis reaction possible. These precipitates were analyzed separately, and the results are shown in Table 5.2. 
Table 5.2. Assay of Cerium Precipitates

\begin{tabular}{|c|c|c|c|c|c|c|c|}
\hline \multirow{2}{*}{ Experiment } & \multirow{2}{*}{$\begin{array}{c}\text { Precipitate } \\
\text { Mass, g }\end{array}$} & \multicolumn{5}{|c|}{ Concentration, $\mu g / g$} & \multirow{2}{*}{$\begin{array}{c}\text { Ratio } \\
\text { V/Al, } \\
\text { ppt }\end{array}$} \\
\hline & & $\mathbf{V}$ & Al & $\mathbf{N i}$ & $\mathbf{S b}$ & $\mathbf{L a}$ & \\
\hline 3 & 0.00210 & 11,500 & 6,300 & 190 & 36,200 & 209 & 1.83 \\
\hline 7 & 0.00168 & 11,000 & 5,420 & 170 & 16,800 & 32.0 & 2.03 \\
\hline 8 & 0.00402 & 13,800 & 7,770 & 114 & 16,900 & 66.2 & 1.78 \\
\hline 9 & 0.00154 & 18,100 & 2,360 & 73 & 29,000 & 59.8 & 7.67 \\
\hline 12 & 0.00307 & 13,200 & 26,500 & 242 & 21,600 & 82.7 & 0.50 \\
\hline
\end{tabular}

Although the total mass of precipitate is small for each sample ( $40.2 \mathrm{mg}$ max), the quantity of antimony is fairly high (3.6\% of the precipitate). The vanadium concentrations in the precipitate are almost as high. Aluminum and lanthanum are relatively low in all but one case (Experiment 12). The concentration of nickel is also low.

Table 5.1 also summarizes the total percent removal of $\mathrm{Al}, \mathrm{V}$, and $\mathrm{Ni}$ from the catalysts that was calculated for each experiment, including the amounts of $\mathrm{Al}, \mathrm{V}$ and $\mathrm{Ni}$ recovered in the precipitates. The data for aluminum and nickel suggest that the amounts extracted are related to the concentration of nitric acid. A linear regression analysis of aluminum with various combinations of the variables confirmed a good correlation between nitric acid and aluminum extracted $\left(R^{2}=0.85\right)$ but no correlation with the other variables. A similar analysis of nickel indicated a fairly good correlation between nitric acid and nickel extracted $\left(R^{2}=0.69\right)$, and a significantly better correlation when both nitric acid and temperature were considered $\left(R^{2}=0.80\right)$. There was no correlation found between nickel extracted and the other variables. A regression analysis of vanadium extraction did not find a significant correlation with any of the variables considered individually or in combination.

Additional experiments were carried out using water at higher temperatures. The conditions and results of these experiments are summarized in Table 5.3. The overall procedure was similar to the extractions from the first set of experiments. However, after extraction was conducted at the given temperature for $1 \mathrm{hr}$ and the effluent collected, the tube was refilled, and the extraction was repeated. This procedure was repeated one or more times to approach an exhaustive extraction at each temperature.

Table 5.3. Effect of Higher Extraction Temperature Using Deionized Water

\begin{tabular}{|c|c|c|c|c|c|c|}
\hline $\begin{array}{c}\text { Experiment } \\
\text { Extraction No. }\end{array}$ & Temperature, $^{\circ} \mathrm{C}$ & $\begin{array}{c}\text { Extraction } \\
\text { Time, min }\end{array}$ & $\begin{array}{c}\text { Effuent } \\
\text { Mass }\end{array}$ & $\begin{array}{c}\text { Wt\% Al } \\
\text { Extracted }\end{array}$ & $\begin{array}{c}\text { Wt\% V } \\
\text { Extracted }\end{array}$ & $\begin{array}{c}\text { Wt\% Ni } \\
\text { Extracted }\end{array}$ \\
\hline $14-1$ & 200 & 56 & 2.87 & 0.00 & 1.50 & 0.01 \\
\hline $14-2$ & 200 & 64 & 2.9 & 0.01 & 1.04 & 0.00 \\
\hline $14-$ total & 0 & 120 & 5.77 & 0.01 & 2.54 & 0.02 \\
\hline $15-1$ & 250 & 61 & 1.78 & 0.01 & 2.28 & 0.00 \\
\hline $15-2$ & 250 & 66 & 1.97 & 0.02 & 1.73 & 0.00 \\
\hline $15-3$ & 250 & 57 & 1.48 & 0.01 & 1.28 & 0.00 \\
\hline 15 - total & 0 & 184 & 5.23 & 0.04 & 5.30 & 0.00 \\
\hline $16-1$ & 300 & 66 & 1.55 & 0.03 & 2.30 & 0.01 \\
\hline $16-2$ & 300 & 71 & 1.7 & 0.02 & 1.43 & 0.03 \\
\hline $16-4$ & 300 & 77 & 2.58 & 0.02 & 0.92 & 0.05 \\
\hline $16-5$ & 300 & 86 & 1.43 & 0.01 & 0.65 & 0.03 \\
\hline $16-$ total & 0 & 300 & 7.26 & 0.08 & 5.30 & 0.13 \\
\hline
\end{tabular}


As shown in Table 5.3, the amount of each species extracted increased with the number of serial extractions, as would be expected for an exhaustive extraction. It can be seen that there is a positive correlation between the temperature of extraction and the amount of aluminum extracted. However, there does not appear to be a correlation between either the extraction temperature or the number of extractions and the total amount of vanadium and nickel extracted.

In order to further explore the effect of temperature on extraction, Extractions 14-1, 15-1, and 16-1 were normalized to $5 \mathrm{~g}$ of extractant similar to the first set of experiments. Table 5.4 summarizes the results, along with the results for Experiments 1 and 2 (also water extractions). With the exception of Experiment 14, there appears to be a positive trend in the extraction of aluminum and vanadium with temperature, but no trend with nickel.

Table 5.4. Summary of Single Extractions with Water at Different Temperatures Normalized to $5 \mathrm{~g}$ of Extractant

\begin{tabular}{|c|c|c|c|c|c|}
\hline Experiment & $\begin{array}{c}\text { Temperature, } \\
{ }^{\circ} \mathbf{C}\end{array}$ & $\begin{array}{c}\text { Extraction } \\
\text { Time, min }\end{array}$ & $\begin{array}{c}\text { Normalized Wt\% } \\
\text { Al Extracted }\end{array}$ & $\begin{array}{c}\text { Normalized Wt\% } \\
\text { V Extracted }\end{array}$ & $\begin{array}{c}\text { Normalized Wt\% } \\
\text { Ni Extracted }\end{array}$ \\
\hline 1 & 100 & 30 & 0.023 & 0.22 & 0.046 \\
\hline 2 & 175 & 90 & 0.022 & 4.71 & 0.42 \\
\hline $14-1$ & 200 & 56 & 0.005 & 2.62 & 0.024 \\
\hline $15-1$ & 250 & 61 & 0.039 & 6.41 & 0.004 \\
\hline $16-1$ & 300 & 66 & 0.088 & 7.41 & 0.046 \\
\hline
\end{tabular}

It is interesting to note that the normalized recoveries of the three species compare favorably with the total amounts recovered with multiple extractions. This suggests that perhaps the additional extractions are not further solublizing the species but rather improving the recovery of the species at their solubility limits. If this is the case, then the quantities presented by the normalized recoveries from a single extraction would represent an upper bound for the amount to be extracted with water.

\subsection{Conclusions}

These experiments demonstrate that the use of strong oxidants in an aqueous medium does not promote the removal of vanadium and nickel from FCC catalysts. The addition of nitric acid improves the removal of nickel but at the expense of removing aluminum from the zeolite. Extraction with pure water achieves a modest removal of vanadium (up to about $7.4 \%$ ) without a significant loss of aluminum from the catalyst. 


\subsection{Supercritical Fluid Extraction of Nickel and Vanadium from Contaminated Zeolite Catalyst}

Supercritical fluid extraction (SFE) may provide a clean and efficient method for removing metal species from contaminated solid materials. Conceptually, such a process would entail loading spent catalyst into a pressure vessel and leaching it with supercritical $\mathrm{CO}_{2}$ containing $5 \%$ methanol and a small quantity of a chelating reagent. The efficiency of metal removal using this technique depends largely on the stability and solubility of the metal chelates formed in the fluid phase. Dithiocarbamate and $\beta$-diketone reagents are known to chelate with a large number of metal ions, including nickel. According to previous experiments, these chelating agents are quite effective for extracting a number of metal ions from solid materials in supercritical $\mathrm{CO}_{2}$ (Laintz et al. 1992; Lin et al. 1993, 1994). Fluorinated chelating agents were found more effective than the nonfluorinated analogs for metal extraction because of the high solubilities of fluorinated metal chelates in supercritical $\mathrm{CO}_{2}$. The presence of water was also found to facilitate the extraction of metal ions using this in situ chelationSFE method.

\subsection{Experiments and Results}

Several experiments were conducted to evaluate the feasibility of extracting nickel and vanadium from the FCC catalyst using supercritical $\mathrm{CO}_{2}$ as a solvent. Chelates investigated were dithiocarbamates, $\beta$-diketones, and porphyrins as chelating agents in supercritical $\mathrm{CO}_{2}$. Specific chelating reagents used were:

- Sodium diethyl dithiocarbamate (DDC) - $\left(\mathrm{CH}_{3} \mathrm{CH}_{2}\right)_{2} \mathrm{NCS}_{2}^{-}$

- Lithium bis(trifluoroethyl)dithiocarbamate (FDDC) $-\left(\mathrm{CF}_{3} \mathrm{CH}_{2}\right)_{2} \mathrm{NCS}_{2}^{-}$

- Hexafluoroacetylacetone (HFA) in tributyl phosphate (TBP)

- 5,10,15,20 tetrakis(pentafluorophenyl)porphyrin (porphyrin I)

- $5,10,15,20$ tetrakis(heptafluoropropyl)porphyrin (porphyrin II)

In two of the experiments a $\mathrm{Ce}$ (IV) compound was added as an oxidant either as $\mathrm{Ce}\left(\mathrm{NO}_{3}\right)_{4}$ or $\left(\mathrm{NH}_{3}\right)_{2} \mathrm{Ce}\left(\mathrm{NO}_{3}\right)_{6}$.

All extraction experiments were performed at the University of Idaho using a laboratory-scale supercritical fluid extraction system described in the literature (Laintz et al. 1992; Lin et al. 1993, 1994). In a typical SFE experiment, $50 \mathrm{mg}$ of spent FCC catalyst were placed in a small glass tube (3 $\mathrm{cm} \times 0.5 \mathrm{in}$. ID) with one end plugged with glass wool. Through the open end, $50 \mathrm{mg}$ of a chelating agent and $50 \mu \mathrm{L}$ of water were added, and the open end was plugged with a piece of glass wool. The loaded sample tube was inserted into a stainless steel extractor $(3.5 \mathrm{~mL}$ in volume) and placed in an oven preheated to $60^{\circ} \mathrm{C}$. The system was pressurized to $200 \mathrm{~atm}$ and extracted statically with $5 \%$ methanol modified $\mathrm{CO}_{2}$ for $15 \mathrm{~min}$ with both the inlet and the outlet valves closed. After the static extraction, the valves were opened to allow supercritical $\mathrm{CO}_{2}$ to flow through the system dynamically for $20 \mathrm{~min}$ with a flow rate of about $2 \mu \mathrm{L} / \mathrm{min}$. After dynamic flushing, the system was depressurized and the sample removed from the extraction cell for chemical analysis. A scanning electron microscopy (SEM) method using an energy dispersive $\mathrm{X}$-ray spectrometry technique was used for analyzing metal contents in the zeolite samples.

The test conditions and experimental results are shown in Tables 6.1 and 6.2. These results cannot be directly compared to the results in the other sections of the report, because a different method of analysis (SEM) is used here, and the percent values are normalized to the totals for those elements 
Table 6.1. Test Conditions for Supercritical Fluid Extraction Experiments

\begin{tabular}{|c|l|}
\hline Test & \multicolumn{1}{|c|}{ Reagents Used $^{(a)}$} \\
\hline 1 & I, $50 \mathrm{mg}$ spent catalyst $+50 \mathrm{mg} \mathrm{NaDDC}+50 \mu \mathrm{L}$ water \\
\hline 2 & $50 \mathrm{mg}$ spent catalyst $+50 \mathrm{mg} \mathrm{LiFDDC}+50 \mu \mathrm{L}$ water \\
\hline 3 & $50 \mathrm{mg}$ spent catalyst $+50 \mu \mathrm{L} \mathrm{HFA}+50 \mu \mathrm{LBP}$ \\
\hline 4 & $50 \mathrm{mg}$ spent catalyst $+50 \mathrm{mg} \mathrm{LiFDDC}+50 \mu \mathrm{L} \mathrm{HFA}+50 \mu \mathrm{L} 2 \mathrm{M} \mathrm{HNO}_{3}$ \\
\hline 5 & $50 \mathrm{mg}$ spent catalyst $+100 \mu \mathrm{L} 0.2 \mathrm{M} \mathrm{Ce}\left(\mathrm{NO}_{3}\right)_{4}$ in $2 \mathrm{M} \mathrm{HNO} \mathrm{HN}_{3}+60 \mu \mathrm{LFA}$ \\
\hline 6 & $50 \mathrm{mg}$ spent catalyst $+20 \mathrm{mg}\left(\mathrm{NH}_{4}\right)_{2} \mathrm{Ce}\left(\mathrm{NO}_{3}\right)_{6}+50 \mathrm{mg} \mathrm{LiFDDC}$ \\
\hline 7 & $50 \mathrm{mg}$ spent catalyst $+6.6 \mathrm{mg}$ porphyrin I $+50 \mu \mathrm{L} 1 \mathrm{M} \mathrm{HNO}_{3}+\mathrm{H}_{2} \mathrm{O}_{2}$ \\
\hline 8 & catalyst $+6 \mathrm{mg}$ porphyrin II $+50 \mu \mathrm{L} 1 \mathrm{M} \mathrm{HNO} \mathrm{HN}_{3}+\mathrm{H}_{2} \mathrm{O}_{2}$ \\
\hline
\end{tabular}

(a) All extractions were conducted using $5.0 \%$ methanol in supercritical $\mathrm{CO}_{2}$ at $60^{\circ} \mathrm{C}, 200 \mathrm{~atm}$.

Table 6.2. Summary of Experimental Results for Supercritical Fluid Extraction Experiments

\begin{tabular}{|c|c|c|c|c|c|c|c|c|}
\hline \multirow{2}{*}{$\begin{array}{c}\text { Test } \\
\text { Number }\end{array}$} & \multirow{2}{*}{ Extractant } & \multicolumn{4}{|c|}{ Catalyst Composition, atom \% } & \multicolumn{2}{|c|}{$\begin{array}{c}\% \\
\text { Extraction }^{(2)}\end{array}$} & \multirow{2}{*}{$\begin{array}{l}\text { Ratio } \\
\text { Al/Si }\end{array}$} \\
\hline & & $\mathbf{V}$ & $\overline{\mathbf{N i}}$ & $\overline{\mathrm{Si}}$ & Al & $\mathbf{V}$ & $\mathbf{N i}$ & \\
\hline$\ldots$ & Fresh Zeolite & 0 & 0 & 67.42 & 27.74 & & & 0.41 \\
\hline$\overline{---}$ & Spent Zeolite & 0.16 & 1.36 & 66.24 & 27.99 & & & 0.42 \\
\hline 1 & $\mathrm{NaDDC}$ & 0.15 & 1.28 & 64.84 & 26.99 & 6.3 & 5.9 & 0.42 \\
\hline 2 & LiFDDC & 0.07 & 1.52 & 64.11 & 26.65 & 56.3 & 0 & 0.42 \\
\hline 3 & HFA, TBP & 0.2 & 1.14 & 67 & 27.5 & 0 & 16.2 & 0.41 \\
\hline 4 & $\begin{array}{l}\text { LiFDDC, HFA, } \\
2 \mathrm{M} \mathrm{HNO}_{3}\end{array}$ & 0.13 & 1.18 & 66.69 & 27.49 & 18.8 & 13.2 & 0.41 \\
\hline 5 & $\begin{array}{l}\mathrm{Ce}\left(\mathrm{NO}_{3}\right)_{4}, \mathrm{HNO}_{3}, \\
\mathrm{HFA}\end{array}$ & 0.31 & 1.08 & 64.31 & 27.25 & 0 & 20.6 & 0.42 \\
\hline 6 & $\begin{array}{l}\left(\mathrm{NH}_{4}\right)_{2}(\mathrm{CeNO})_{6} \\
\mathrm{LiFDDC}\end{array}$ & 0.37 & 0.92 & 58.2 & 25.45 & 0 & 32.4 & 0.44 \\
\hline 7 & $\begin{array}{l}\text { porphyrin I, } \\
\mathrm{HNO}_{3}\end{array}$ & 0.22 & 1.23 & 67.54 & 26.79 & 0 & 9.6 & 0.40 \\
\hline 8 & $\begin{array}{l}\text { porphyrin II, } \\
\mathrm{HNO}_{3}\end{array}$ & 0.27 & 0.96 & 67.81 & 27.18 & 0 & 29.41 & 0.41 \\
\hline
\end{tabular}

(a) The \% extracted is based on the concentrations in the treated catalyst with respect to the concentrations on the spent catalyst. There was no mass balance performed.

evaluated in Table 6.2, whereas the XRF analysis values are normalized to the total sample composition.

The results of the SFE tests are shown in Table 6.2. Several observations can be made regarding the use of the chelates. Generally each chelate either removed vanadium or nickel but not both. It appears that LiFDDC promoted removal of vanadium from the sample (Tests 2 and 3 ) and HFA promoted removal of nickel (Tests 3,4 , and 5). 
However, when the two are used together, both nickel and vanadium were extracted but in lower amounts compared to the individual extractants. Porphyrin II also appeared to remove nickel and achieved one of the best results of the chelates (Test 8). On the other hand, the use of ammonium ceric nitrate achieved the highest nickel extraction results when used together with LiFDDC, but the combination apparently completely inhibited the extraction of vanadium by the LiFDDC. For the most part, the chelates did not appear to significantly remove aluminum, but there may have been significant loss of silica when the ammonium ceric nitrate/LiFDDC combination was used (Test 6).

\subsection{Conclusions}

These results suggest that LiFDDC could be an effective chelate for removing vanadium and that HFA or porphyrin II would be possible chelates for removing nickel in SFE using $5 \%$ methanol modified $\mathrm{CO}_{2}$. In addition, ammonium ceric nitrate was a possible extractant for this SFE system. However, it is also clear that removal of both metals would require separate steps using different extractants. 


\subsection{References}

Higgins, T. L. 1996. "Refiners Focus on FCC Catalysts at Q\&A Meeting." Oil and Gas Journal 94(23):49.

Laintz, K. E., C. M. Wai, C. R. Yonker, and R. D. Smith. 1992. Anal. Chem. 64:2875.

Lin, Y., R. D. Brauer, K. E. Laintz, and C. M. Wai. 1993. Anal. Chem. 65:2549.

Lin, Y., C. M. Wai, F. M. Jean, and R. D. Brauer. 1994. Environ. Sci. Technology 28:1190.

Oil \& Gas Journal. 1998. "Refining Wastes Added to Hazards List." 96(28):35-36. 
Appendix

Regeneration of Catalysts Used in Processing Residual-Oil-Type Feedstocks 


\section{Appendix \\ Regeneration of Catalysts Used in Processing Residual-Oil-Type Feedstocks}

\section{Background}

The primary purpose of processing residual-type oil fractions (atmospheric residuum or vacuum residuum, asphalt pitch, tar oil, coal liquefaction oil, and oil shale kerogen) is to convert high boiling point material into low boiling point material, while at the same time optimizing the resulting oil products according to market forces (gasoline, diesel fuel, fuel oil, etc.). Today, one of the major factors affecting this mix of products is an increased demand for high octane gasoline and lower demand for fuel oil, although the demand for each varies seasonally, with gasoline demand greatest in the summer, and fuel oil demand greatest in the winter. Coupled with this objective is the need to process heavier crude oil feedstocks to meet current demand, because the availability of lighter crude oil is diminishing.

Treatment of residual-type oils presents unique processing challenges. The relatively high temperatures required to process the oil create opportunities for the oil to pyrolyze to coke and an even heavier asphalt like oil, while evolving light gases that are less suitable feedstocks for gasoline production. Along with this phenomenon is the fact that these oils contain a relatively high concentration of organometallic compounds, whose metals are catalytically active at these temperatures. These oils also contain relatively high concentrations of heterocyclic compounds containing nitrogen, oxygen, and sulfur that tend to form coke precursors during processing and which are undesirable compounds in oil products. All of these heterocarbon compounds create problems for catalytic processing because of their propensity to deactivate the catalysts.

\section{Processes Used to Treat Residual-Type Oil}

There are a number of processes used to treat residual-type oil. Several general categories of these processes are shown in Table A.1. The key process parameters for all of these processes, except deasphalting, are temperature, hydrogen pressure, space velocity, feedstock recycle ratio, catalyst type and age, and feedstock characteristics.

The specific combination of processes used to treat residual oil types at a specific oil refinery is generally dictated by the characteristics of the crude oil being refined and the processes that are already in place. The latter factor is important because the high capital cost of building new processes drives the industry to adapt an existing process, even though a new plant with a different combination of processes might be more efficient and cost effective.

All of the catalytic processes involve several reaction mechanisms including adsorption; hydrogenolysis of R-S, R-N, R-O and R-M bonds; cracking and desorption of product hydrocarbons, $\mathrm{H}_{2} \mathrm{~S}, \mathrm{~N}_{2}\left(\mathrm{NH}_{3}\right)$ and $\mathrm{H}_{2} \mathrm{O}$; and deposition of the metal on the catalyst.

Dehydrogenation and hydrogenation take place to varying degrees, depending on the presence of hydrogenating metals and the partial pressure of hydrogen. Metals in the feedstock that are deposited, in particular nickel and vanadium, are catalytic to this mechanism, irrespective of the metals incorporated during catalyst synthesis. Coke formation primarily involves the cracking mechanism causing carbon chain-length growth on the catalyst acid sites to form polycylic unsaturated compounds that slowly dehydrogenate to form a graphite-like coke. At high hydrogen partial pressures (600-3000 psig), the 
Table A.1. Processes Used to Treat Residual-Type Oil

\begin{tabular}{|c|c|c|c|c|c|c|c|c|}
\hline Process & Temperature, ${ }^{\circ} \mathrm{C}$ & $\begin{array}{l}\text { Pressure, } \\
\text { psig }\end{array}$ & $\begin{array}{l}\text { Reacting } \\
\text { Gases }\end{array}$ & Catalyst & $\begin{array}{l}\text { Space } \\
\text { Velocity }\end{array}$ & $\begin{array}{l}\text { Catalyst } \\
\text { Life }\end{array}$ & $\mathrm{H}_{2} / \mathrm{Oil}, \mathrm{m}^{3} / \mathbf{L}$ & References \\
\hline $\begin{array}{l}\text { Fluid Catalytic } \\
\text { Cracking }\end{array}$ & $\begin{array}{l}\text { Rx: } 470-525 \\
\text { Regen: } 560-600\end{array}$ & $10-16$ & none & $\begin{array}{l}\text { REY-Zeolite in } \\
\text { Silica-Alumina }\end{array}$ & $\begin{array}{c}1-3 \\
w t / h r / w t\end{array}$ & & & 3 \\
\hline Hydrotreating & $\begin{array}{l}\text { Rx: } 382-415 \\
\text { Regen: } 370-650\end{array}$ & $\begin{array}{l}600- \\
3,800\end{array}$ & $\mathrm{H}_{2}$ & $\begin{array}{l}\text { Ni-Mo-S } \\
\text { Co-Mo-S } \\
\text { Ni-W-S } \\
\text { Co-W-S (all on } \gamma- \\
\text { Alumina) }\end{array}$ & $\begin{array}{c}0.4-1.5 \\
\mathrm{v} / \mathrm{hr} / \mathrm{v}\end{array}$ & $\begin{array}{c}2-5 \text { yr with } \\
\text { regeneration } \\
50 \text { to } 100 \\
\text { times/ life }\end{array}$ & $1,000-2,000$ & 2,3 \\
\hline Hydrocracking & $R x: 390-482$ & $\begin{array}{l}1,800- \\
3,000\end{array}$ & $\mathrm{H}_{2}$ & $\begin{array}{l}\mathrm{Ni}, \mathrm{Co}, \mathrm{Mo}, \mathrm{W}, \mathrm{V}, \\
\text { Pd, Pt (single or in } \\
\text { combination) on } \\
\text { amorphous Si-Al, } \\
\text { Zeolite, } \gamma- \\
\text { Alumina }\end{array}$ & $\begin{array}{l}0.3-1.5 \\
\mathrm{v} / \mathrm{hr} / \mathrm{v}\end{array}$ & & $1,400-1,600$ & $1,2,3$ \\
\hline Visibreaking & $\mathrm{Rx}: 500-525$ & $10-100$ & none & None & $0.042 / \mathrm{hr}$ & NA & NA & 2,3 \\
\hline $\begin{array}{l}\text { Coking/ } \\
\text { Delayed Coking }\end{array}$ & $R x: 480-560$ & $0-60$ & none & none & $\begin{array}{c}120-210 / \mathrm{hr} \\
(\text { delayed } \\
\text { coking, 24-hr } \\
\text { cycle) }\end{array}$ & NA & NA & 2 \\
\hline Deasphalting & NA & NA & none & none & NA & NA & NA & \\
\hline
\end{tabular}

(1) Hatch and Mater (1981).

(2) Schuetze and Hoffman (1984).

(3) Bland and Davidson (1967). 
carbon chain-length growth mechanism is mitigated because the hydrogen promotes saturation of adsorbed hydrocarbon species produced during cracking, thus producing hydrocarbon compounds more easily desorbed from the surface sites.

\section{Fluid Catalytic Cracking}

The one process that is common to virtually all refineries for processing the heavier crude oil fractions is catalytic cracking, with fluid catalytic cracking (FCC) being the more common process configuration (the moving bed catalytic cracker being the older process). The purpose of the FCC process is to increase the yield of gasoline from light and heavy gas oils, naphtha, and some residual oil. Compared to the older thermal cracking processes, FCC produces hydrocarbons with high anti-knock properties, reduces the formation of olefinic hydrocarbons (which form gum deposits in gasoline), and reduces the formation of methane and $C_{2}$ hydrocarbon gases in favor of $C_{3}$ and $C_{4}$ hydrocarbons used in LPG. The main limitation of the FCC process is that it produces coke deposits that quickly deactivate the catalyst, requiring it to be regenerated. It is also poisoned by metals in the feed, resulting in the need to replace the catalyst on a daily basis.

Feedstocks high in metal content can be pretreated to reduce their concentrations to levels amenable to the FCC process. These processes include deasphalting, hydrotreating, and hydrocracking. Deasphalting processes use a selective organic solvent such as pentane to separate the residual oil into low and high asphalt fractions. The metals in the oil asphalt report to the high asphalt fraction. Both the hydrotreating and hydrocracking catalysts remove the metals from the residual oil by depositing these materials on the catalysts, which are more tolerant of the metals.

FCC catalysts consist of finely divided $(\sim 1-5 \mu \mathrm{m})$ lanthanide substituted X-or Y-type zeolite immeshed in amorphous silica alumina particles $(\sim 50 \mu \mathrm{m})$ (the Philips Petroleum sample is a Y-type zeolite). The catalyst is typically made by first preparing the sodium zeolite from sodium aluminate and sodium silicate in a caustic solution, filtering and drying the resulting zeolite, and then adding the lanthanide trichloride in an ammonium chloride solution to exchange the lanthanide and ammonium cations for the sodium. The zeolite is mixed with freshly prepared amorphous silica-alumina hydrogel and then spray dried and washed (Venuto and Habib 1979). The method of preparation of the zeolite reduces the exchangeable sodium content by exchanging with hydrogen cations (ammonium cation prior to drying) and replacing the nonexchangeable sodium with lanthanide. Upon drying in the spray dryer, lanthanum enters the sodalite cages that make up the macro-cage structure of the zeolite, removing the nonexchangeable sodium cation and making a very stable cage structure. The amorphous alumina silica gel is used to produce the proper size of particle and to make a stronger particle than is possible with just the zeolite.

\section{Hydrotreating}

Hydrotreating processes are used primarily for reducing sulfur in petroleum products. In addition, the processes are used to reduce the nitrogen and oxygen content present in some crude oils, as well as to remove metals. The hydrotreating processes are also variously known as hydrodesulfurization (HDS), hydrodenitrogenation ( $\mathrm{HDN})$, hydrogenolysis $(\mathrm{HDH})$, and hydrodemetallization (HDM), usually dictated by the characteristics of the feedstock, although all subprocesses take place to varying degrees on different hydrotreating catalysts. Hydrotreating processes are designed to minimize cracking reactions to minimize coke formation and hydrogen consumption.

Hydrotreating is accomplished in fixed and ebullated bed (or expanded slurry) reactors. The fixed bed is the more widely used configuration and has the advantages of 1) better temperature control, 2) wider 
operating flow range, and 3) little or no catalyst attrition. Disadvantages include 1) non-isothermal operation with the requirement of a quench system to limit the temperature increase across the bed; 2) gradients of coke, metals, and other poisons; and 3) high pore diffusional resistance and mass transport limitations. The advantages of the ebullated bed include 1) isothermal operation with no quenching and, consequently, less coking; 2) elimination of mass transport limitations; 3) no blockage of flow as in a fixed bed; and 4) more uniform deposition of coke and poisons across the bed and catalyst particles, thereby minimizing plugging of the catalyst, although metal gradients in catalysts still persist.

Disadvantages include 1) must be closely monitored to prevent thermal runaway, 2) suffers from catalyst attrition, and 3) requires sophisticated equipment for separating the catalyst fines from the product (Bartholomew 1994).

The most common hydrotreating catalysts are NiMo, CoMo, and NiW catalysts on an $\gamma$-alumina support. A small quantity of silica is included to provide better hydrocracking characteristics, and phosphorous (phosphate), boron, and titanium are also added to stabilize the alumina support, making nickel and cobalt diffusion less likely. A number of other transition and noble metals are also catalytic for hydrodesulfurization ( $\mathrm{Pt}, \mathrm{Ru}, \mathrm{Rh}, \mathrm{Pd}, \mathrm{V}, \mathrm{Fe}, \mathrm{Mn}$ and $\mathrm{Cr}$ ), but do not appear to be used commercially. Similarly, the binary metals can be used without a support. The specific catalyst used in hydrotreating is largely determined by the characteristics of the oil. Individually, $\mathrm{Ni}$ and $\mathrm{Co}$ are not good HDS or HDN catalysts compared to Mo, but when combined in solid solution with the latter the Mo specific activity is increased by factor of 2 to 10 . CoMo catalysts are generally more active for HDS, and NiMo catalysts are generally more active for HDN. The more expensive NiW catalyst is used in instances where high saturation and moderate cracking of low-sulfur feedstock are desired [McCulloch (1983); Bartholomew (1994) in Oballa (1994)]. Catalysts typically range in size from $0.8-4 \mathrm{~mm}$ diameter to $2-4 \mathrm{~mm}$ long as extrudates.

Preparation of hydrotreating catalysts generally consists of impregnating the respective metal salts on the catalyst support, calcining the treated support at $400^{\circ} \mathrm{C}$ to $600^{\circ} \mathrm{C}$, and then sulfiding the catalyst (Wiesser and Landa 1973). The different catalyst metals may be impregnated simultaneously or sequentially. Metals may also be precipitated onto the catalyst support, again either sequentially or simultaneously (coprecipitation).

\section{Hydrocracking}

Hydrocracking processes are used to convert residual oil into lower boiling fractions. These processes are particularly suited for feedstocks high in coke precursors (aromatics, polyaromatics, and asphaltenes), sulfur, nitrogen, and metals. Hydrocracking processes can be tailored to maximize different products such as low sulfur fuel oil, lubricating oils, jet fuel, and diesel fuel. Hydrocrackers may consist of one or two stages. In the more common single-stage hydrocracker, all reactions take place in a single reactor before product fractionation. In a two-stage process, hydrodesulfurization and hydrodenitrogenation take place along with some cracking in the first vessel before fractionation.

The heavy fraction is further cracked to maximize diesel or jet fuel. Hydrocracking reactor configurations include fixed bed, fluidized bed, and entrained (ebullated) bed. The main difference between the fluid and entrained beds is the average residence time and residence time distribution of the catalyst.

Hydrocracking catalysts include $\mathrm{Ni}, \mathrm{Co}, \mathrm{Mo}, \mathrm{W}, \mathrm{V}, \mathrm{Pd}, \mathrm{Pt}$ (individually or up to 3 in combination) on amorphous silica-alumina, zeolite, other molecular sieves and $\gamma$-alumina). The base metals are usually presulfided on the catalyst. Pd and Pt are reduced on the catalyst and then used in the reduced metal or sulfide form. Hydrocracking catalysts differ from hydrotreating catalysts in that a much larger 
concentration of acid sites is provided by using the silica-alumina and zeolite supports. However, the concentration of acid sites varies on the desired product slate (more cracking and isomerization favored by strong acid site activity, hydrogenation favored by less active sites), and the lower acid catalysts such as $\gamma$-alumina may be used.

\section{Visibreaking/ Coking/ Delayed Coking}

Visibreaking and the two coking processes are mentioned here because they are also used in some refineries to treat residual-type oil and, therefore, provide feedstock for the other processes. Visibreaking is a mild thermal cracking process whose objective is to convert residuum into lighter fractions such as fuel oil, middle distillates, and feedstock suitable for catalytic cracking. In effect, this process improves the thermal and chemical properties of residual oil without using hydrogen or producing large quantities of coke. Coking and delayed coking are severe thermal cracking processes used to produce light products and coke from feedstock otherwise not suitable for catalytic cracking, usually because of their high asphaltene and metals content. The products from coking are usually hydrodesulfurized to reduce sulfur and olefin content. The desulfurized coke is sold as a product for producing electrolytic anodes and synthetic graphite.

\section{Catalyst Consumption}

In 1987 , catalytic processes consumed over 500 tons of solid catalysts daily to process approximately $1 / 3$ of all processed oil in the United States. Table A.2 summarizes the estimated usage and costs of all catalysts used in petroleum refining in 1987.

Table A.2. Estimated U.S. Refining Catalyst Usage in 1987 (Occelli 1988)

\begin{tabular}{|l|c|c|c|c|c|c|}
\hline Refining Process & $\begin{array}{c}\text { U.S Capacity, } \\
\text { million bbl/yr }\end{array}$ & $\begin{array}{c}\text { Catalyst } \\
\text { Consumption, } \\
\mathbf{l b / b b l}\end{array}$ & $\begin{array}{c}\text { Catalyst } \\
\text { Consumption, } \\
\text { million lb/yr }\end{array}$ & $\begin{array}{c}\text { Catalyst } \\
\text { Cost, } \\
\text { S/b }\end{array}$ & $\begin{array}{c}\text { Catalyst Cost, } \\
\text { \$/bbl }\end{array}$ & $\begin{array}{c}\text { Catalyst Cost, } \\
\text { millionS/yr }\end{array}$ \\
\hline Cat. Cracking & 4.9 & 0.2 & 360 & 0.70 & 0.14 & 250 \\
\hline $\left.\begin{array}{l}\text { Alkylation, } \\
\left(\mathrm{H}_{2} \text { SO }\right.\end{array}\right)$ & 0.5 & 18 & 3,000 & 0.03 & 0.54 & 99 \\
\hline Hydrotreating & 8.4 & 0.009 & 28 & 3.00 & 0.03 & 84 \\
\hline Hydrocracking & 1.0 & 0.013 & 4.7 & 10.00 & 0.13 & 47 \\
\hline Cat. Reforming & 3.5 & 0.0033 & 4.2 & 6.5 & 0.02 & 27 \\
\hline Alkylation (HF) & 0.4 & 0.15 & 22 & 0.70 & 0.11 & 15 \\
\hline Isomerization & 0.25 & 0.015 & 1.4 & 6.00 & 0.09 & 8 \\
\hline Oligomerization & 0.05 & - & - & - & - & - \\
\hline
\end{tabular}




\section{Function and Behavior of Catalyst Constituents}

\section{Catalyst Properties}

Two of the more important properties of these catalysts are acidity and pore size distribution. Cracking catalysts (FCC and hydrotreating) make use of the presence of Brønsted acid sites to promote cracking. Zeolite catalysts and, more specifically, Y-zeolites are the most common catalytic materials used because of their high concentration of acid sites and relatively stable chemical properties. Amorphous materials and, in particular, $\gamma$-alumina contain a much lower concentration of Brønsted sites and are chemically and mechanically quite stable. FCC and hydrocracking catalysts utilize zeolites for their cracking catalytic properties and amorphous material for catalyst mechanical strength.

Hydrotreating catalysts use only the amorphous material to minimize cracking while providing a support for metal catalysts (Ni, Co, W, Mo) that promote desulfurization and/or denitrogenation. Tungsten and molybdenum sulfides create the catalytic sites on the hydrotreating catalysts by forming very small platelike crystallites that attach on their flat side or on their edge to the alumina support.

The nickel-molybdenum catalysts consist of an alumina support upon which molybdate is deposited. At low concentrations, isolated tetrahedrally bound molybdenum is deposited directly on the alumina. As more molybdenum is added these deposits grow laterally, forming single-layered platelets of polymeric molybdenum oxide. At even higher loadings, some of the layers will grow vertically, forming multilayered platelets consisting of octahedrally bound molybdenum. The sulfided form of this arrangement is shown schematically in Figure A.1. HDS hydrogenation reactions are believed to take place on the edge and corner sites of the Mo layers (Massoth et al. 1984; Pratt et al. 1980). Stanley (1988) cited several studies that suggest that the molybdenum is incompletely sulfided under most processing conditions, and that oxidation states of 4,5 , and 6 have been observed. These sites are expected to possess the more reduced forms of Mo (Hiltzik 1987).

According to Prins et al. (1989), and as confirmed by Startsev (1995) through their review of work by others, the nickel and cobalt attach to the edges of the crystallites, but do not migrate into the interior of the crystallites. The stoichiometry of the crystals depends on the size and orientation of the $\mathrm{MoS}_{2}$ crystallites, with edge attachment to the alumina support producing the greatest number of sites/crystal. The nickel can also deposit directly on the surface of the alumina as NiS or enter into the interior of the alumina forming $\mathrm{NiAlO}_{3}$. Neither of these forms is active, and the latter form is irreversibly formed. The $\mathrm{NiS}$ can serve as a nickel source for the $\mathrm{MoS}_{2}$ crystal edge site in subsequent regeneration as some nickel migrates into the catalyst support, but some of this nickel will form nickel sulfate, which is also inactive.

\section{Catalyst Deactivation Mechanisms}

Catalyst deactivation occurs by three simultaneous mechanisms: coking, metals deposition, and substrate interactions. The specific rates of deactivation for each mechanism and each process depends to a large extent on the properties of the catalyst; hydrogen partial pressure; characteristics of the feedstock; and conditions, frequency, and manner of catalyst regeneration to remove coke deposits. The manner and frequency of catalyst regeneration to remove coke is important because it affects the oxidation states of the deposited metals and is responsible for many of the substrate interacations with them. 


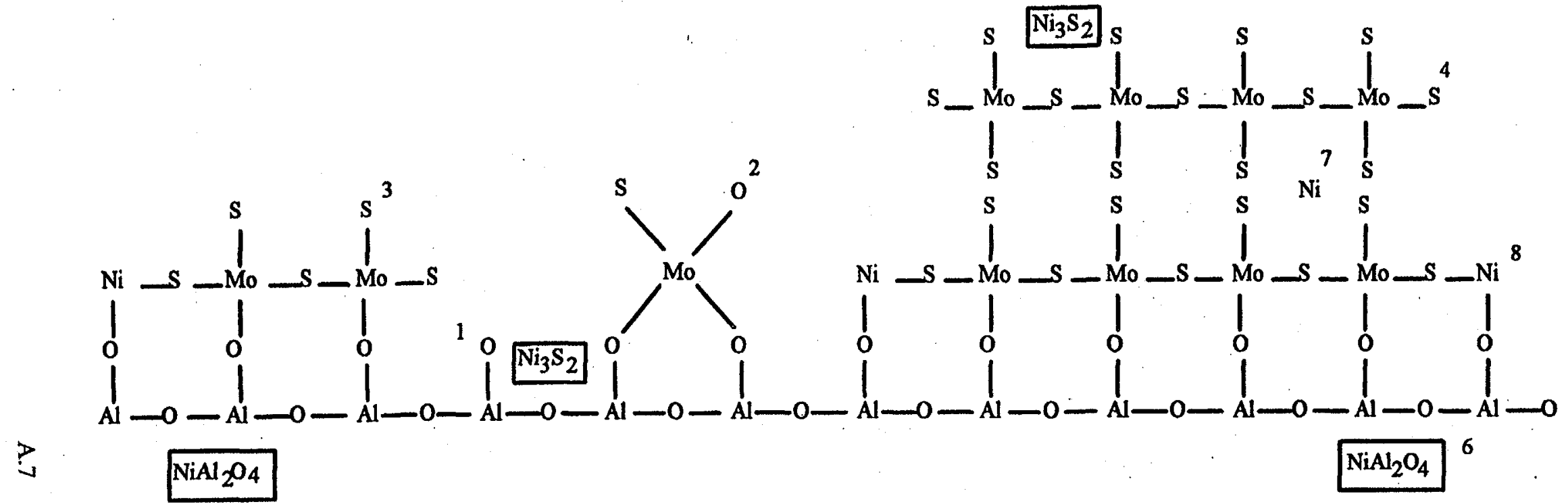
1. Bare Support Surface
5. Bulk Nickel Oxide
2. Isolated Tetrahedral Mo
6. Surface or Subsurface Nickel Aluminate
3. Single-Layered, Polymeric Mo
7. Octahedral Ni in $\mathrm{Mo}$
4. Jultilayered Octahedral Mo
8. Tetrahedral $\mathrm{Ni}$ in $\mathrm{Mo}$

Figure A.1. Side View Representation of Nickel and Mo Loading for a Ni/Mo Catatalyst on an Alumina Support (Stanley 1988) 


\section{Overview}

The deactivation sequence differs between the FCC catalysts and the hydrotreating and hydrocracking catalysts. This difference is largely due to the frequency of catalyst regeneration and its impact on the zeolite catalyst.

The FCC process uses a zeolite catalyst to crack hydrocarbons to lighter compounds in the absence of high hydrogen partial pressures. As a consequence, coke is built up very rapidly on the active sites of the catalyst, requiring the catalyst to be regenerated continuously to remove the coke. At the same time, any metals in the feedstock are deposited on the catalyst. Catalyst that is removed from the catalytic cracker is steam-stripped of volatile hydrocarbons before entering the regenerator where dilute oxygen is used to burn off the coke before it goes back to the catalytic cracker. Deactivation of the catalyst can occur for several reasons. For example, the deposits of nickel and vanadium accumulate and plug some of the smaller pores in the catalyst. These metals are also good dehydrogenation catalysts and accelerate the rate of coking in the cracker unit, which reduces its average performance in this unit. Also occurring as a result of the frequent regeneration are interactions between the steam, metal deposits, and the zeolite that can eventually lead to a loss of the zeolite's physical stability.

The general sequence of deactivation of hydrotreating and hydrocracking catalysts takes place in three stages. In the first stage, the catalyst is initially coked with soft coke and soluble coke, losing perhaps $25 \%$ to $30 \%$ of its initial activity over a relatively short period of time (about $10 \%$ to $20 \%$ of the catalyst life). The second stage is dominated by metal deposition, which occurs over a relatively long period of time (about $70 \%$ of the catalyst life). Gradual dehydrogenation of the coke deposits takes place during this period, ultimately leading to formation of a hard crystalline coke, which contributes to plugging. In the third stage, the pore entrances become plugged by the heavy metals, rapidly reducing the remaining available surface area and resulting in a relatively rapid decline in catalyst activity (about $30 \%$ of the catalytic activity over about $20 \%$ of the catalyst life). The required reactor operating temperature is inversely related to the activity profile with a typical increase of about $50^{\circ} \mathrm{C}$ over the life of the catalyst. Periodically during the second stage the catalyst may be regenerated to remove some of the coke to extend the catalyst life.

\section{Coke Deposition}

Coking is a somewhat complex mechanism dictated to an extent by the type of catalyst and the hydrogen partial pressure. Coking is promoted by acid sites on the support and the presence of catalytic metals. Deactivation due to coke deposition is the primary deactivation mechanism during process operation.

For FCC catalysts, hydrocarbon cracking in the absence of a high partial pressure of hydrogen causes much more coke formation than the hydrotreating and hydrocracking catalysts. Coke formation further catalyzed by nickel and vanadium contaminants, which promote dehydrogenation reactions that occur in a matter of seconds and lead to very rapid deactivation of the catalyst. FCC catalyst deactivation by coking is very rapid, limiting catalyst residence times to about 5 seconds in the riser section of the FCC unit where feedstock is cracked. Coke levels on the order of $9 \%$ are obtained in the riser section.

Hydrotreating and hydrocracking catalysts coke very slowly because of the high hydrogen partial pressures, even though the latter catalyst has a higher concentration of acid sites. These catalysts are infrequently decoked (on the order of months). 
Coke deposits on the catalyst appear to consist of three different forms. The first form consists of strongly but reversibly bound aromatic hydrocarbons, such as benzene and naphthalene, as well as polynuclear aromatics (produced by polymerization of benzene and naphthalene). The second form is produced by the thermal decoupling of asphaltic clusters and subsequent binding onto a catalyst surface sulfur site. The third form consists of polynuclear aromatic mesophase crystals formed from the asphaltenes [Beuther et al. (1980) quoted by Bartholomew (1994)].

Cumming and Wojciechowski (1996) provided a rather extensive review and interpretation of the literature regarding the formation of the first and third forms of coke and at least implied the mechanism of the formation of the second form. According to Cumming and Wojciechowski, the initial coke formation is a relatively minor reaction taking place on the acid sites of the catalyst. While the majority of the surface reactions involve adsorbed carbonic ions on Bronsted sites and bulk phase hydrocarbons, a small portion of the carbonic ions react with each other if they occupy neighboring lattice sites. This causes disproportionation, and desorption of one of the resulting ions may be replaced by the other ion that is now attached at two acid sites. Alternatively, an olefin carbonic ion can either attach directly to an adjacent lattice site forming a bridging di-ion or cyclize on the original site, the latter eventually leading to aromatization of the ion. The di-ions are more tightly sorbed onto the surface and are much less reactive with bulk-phase hydrocarbons and effectively deactivate the affected catalyst sites. As the density of remaining active sites decreases, the rate of deactivation also decreases, as there are less adjacent lattice sites available for the mechanism. However, these species can be desorbed from the surface, thereby resulting in a reactivation of the affected sites. It is also possible for the di-ions to continue to bridge to adjacent sites, provided they are sufficiently long. Eventually, the ion bridge assembles into an island of dehydrogenated polyion species that are very difficult to desorb and are increasingly less reactive due to increasing resonance in the structure. At the same time, elimination of hydrogen and methane groups lead to even more unsaturated entities resembling complex condensed polyaromatics. Polymeric coke is relatively unreactive and is not removed completely during periodic decoking. Therefore, this form of coke contributes to plugging of the catalyst pores.

\section{Metals Deposition}

Nickel and vanadium metals originate as organometallic compounds (e.g., porphyrins) coordinated with polynuclear aromatics inside asphaltene micelle clusters of 4-5 nm diameter (Bartholomew 1994). As these compounds are decomposed, the metals are deposited. In hydrotreating and hydrocracking catalysts, the metal deposits are sulfided by the sulfur in the feedstock. In FCC catalysts, the metal deposits are converted to oxides during regeneration.

In hydrocracking and hydrotreating catalysts, vanadium is removed from the feedstock preferentially to nickel, so that the vanadium is deposited in greater concentrations. FCC catalysts are often used on previously demetallized oil, so that nickel deposition is more pronounced and may exceed that of vanadium. The process of feedstock decomposition is rapid relative to diffusion; the metals are preferentially deposited on the pore entrances and towards the outside of the catalyst extrudate. Vanadium, nickel, arsenic, and lead are all deposited this way. Metals deposition also preferentially occurs in the upper part of a fixed bed. Consequently, when the catalyst is regenerated to remove coke the recovery of surface area and pore volume ranges from $10 \%$ to $60 \%$, depending on the location of the catalyst in the bed (Bartholomew 1994).

The deposition of transition metals $(\mathrm{Ni}$ and $\mathrm{V}$ ) is a gradual and cumulative process causing a slow decrease in catalyst activity. Silbernagel (1979) showed that, for vanadium (IV) deposits on the catalyst at levels $<0.7 \%$, the vanadium is deposited in the alumina defects. At deposited concentrations up to 
about $10 \%$, the vanadium is deposited as an oxysulfide layer, and at concentrations above $10 \%$ the vanadium is deposited as $\mathrm{V}_{2} \mathrm{~S}_{3}$. Nickel deposits on $\mathrm{Co} / \mathrm{Mo}$ catalysts are deposited as $\mathrm{Ni}_{3} \mathrm{~S}_{2}$ as opposed to NiS or Ni metal (Rankel and Rollman 1983; Fleisch et al. 1984).

Deposition does not appear to occur on the active metal sites of the catalyst in the case of hydrotreating and hydrocracking catalysts, probably because these sites are on the edges and corners of molybdenum crystallites where they meet the alumina support. Instead, the metals deposit on the basal planes of the crystallites and directly on the support where there are no crystallites. The gradual deactivation of the catalyst by this mechanism appears to occur because the smaller pores are plugged first, leaving a significant portion of unplugged pores. Ultimately, the larger pores become plugged and the catalyst deactivates.

In the case of FCC catalysts, the adverse catalytic activity of nickel and vanadium limits the useful life of the catalyst well before plugging from metals deposition is a problem.

\section{Other Deposits}

Iron and sodium salts are initially present in the oil as particulate matter and deposit on the outside of the catalyst extrudate. These metals can plug the outer pores and interstitial spaces in the beds. Lead may also deposit, but, like arsenic, it is very low in concentration relative to vanadium, nickel and iron. Lead also deposits reversibly, so feedstocks can handle up to $100 \mathrm{ppm}$ (Bartholomew 1994). Other impurities that may be deposited to any of the catalysts include silica (from antifoaming agent addition to some oils), sulfates, and chlorides.

Antimony may be added as an oil-soluble organometallic compound to FCC catalyst during operation to deactivate the Ni metal. This has been practiced in the past by Philips Petroleum (Hatch and Matar 1981), and is noted in the analysis of spent catalyst samples. As much as $0.5 \% \mathrm{Sb}$ may be added; presumably this also contributes to the pore blockages (McCulloch 1983).

\section{Substrate Interactions}

Substrate interactions include interactions between the zeolites or support material (alumina) and the metals and reactive gases that lead to physical and chemical degradation of these materials. The main phenomenon that occurs relates to the propensity of zeolites and other alumina silicates, alumina, and silica to allow substitute species within their crystal framework structures. In the case of zeolites, an important consequence can be the loss of acid sites, thereby deactivating the material towards cracking.

FCC catalyst deactivation of this type occurs by several mechanisms. First, the catalyst undergoes some permanent deactivation due to steam migration of silica in the zeolite during the first hot cycles of the catalyst. This occurs after the catalyst discharges to the vessel outside of the riser section where it is steam-stripped to remove volatile hydrocarbons prior to being decoked. This leads to some loss of porosity of the amorphous silica-alumina and possibly partial collapse of those portions of the zeolite structure that were not stabilized with lanthanides. The loss of activity is correlated with the loss of surface area and pore volume and an increase in the specific gravity of the catalyst.

After steam-stripping, the discharged FCC catalyst is decoked using air or diluted oxygen in the regenerator to reduce carbon content to about $0.2 \%$. At the same time, vanadium, which is primarily deposited in the +4 oxidation state, is converted to the +5 state as $\mathrm{V}_{2} \mathrm{O}_{3}^{-}$. During subsequent exposures to 
steam-stripping the vanadate becomes very mobile, presumably as vanadic acid and interacts with the rare earth catalysts, forming a salt and displacing alumina in the zeolite structure. This phenomenon is less severe in the hydrotreating and hydrocracking processes because regeneration takes place less frequently.

In hydrotreating and hydrocracking catalysts, the active metals $(\mathrm{Mo}, \mathrm{Ni}$, and $\mathrm{Co}$ ) can migrate into the support material, which reduces their inventory on the support surface. These migrations cause changes in the substrate structure, but may not necessarily be detrimental. Vanadium (IV) is not particularly mobile in these materials; however, during decoking, vanadium is oxidized to $+5 \mathrm{form}$, which is mobile in the support and is not reduced during the hydrotreating/cracking stages of the cycle. The metals that migrate into the support lose their catalytic activity.

Vanadium deposited in the +4 state is oxidized to the +5 state during regeneration, and is very mobile in the presence of steam. Under these conditions the vanadium attacks as an acid and removes the aluminum from the structure. The vanadium will also react with the lanthanum to produce free $\mathrm{LaVO}_{4}$.

Hydrotreating catalysts are operated over a long period of time (on the order of 1 to 2 years), in which the buildup of soft coke is transformed into a hard crystalline coke (Bartholomew 1994), and the Ni, V, and Fe contaminants, along with the carbon, build up to levels that plug a large fraction of the catalyst pores. Regeneration of the catalyst to remove carbon deposits can lead to redistribution of Mo on the catalyst site, particularly if steam is present. Arteaga et al. (1987) subjected sulfided commercial CoMo catalyst to regenerating conditions $\left(5 \% \mathrm{O}_{2}\right.$ and $6.8 \% \mathrm{H}_{2} \mathrm{O}$ in $\mathrm{N}_{2}$ ) at regeneration temperatures of $400^{\circ} \mathrm{C}$ to $700^{\circ} \mathrm{C}$, and then reactivated the catalyst. They showed that in the presence of steam the hydrogenation and hydrodesulfurization activity of the catalyst following regeneration decreased significantly compared to similar experiments performed in the absence of steam. There was evidence that a portion of the Mo was not resulfided following regeneration at the higher temperatures. They also showed that Co experienced a much more significant loss of resulfided $\mathrm{Co}$ and a corresponding increase in cobalt oxide. These effects are attributed to a redistribution of $\mathrm{MoO}_{3}$, in the form of $\mathrm{MoO}_{2}(\mathrm{OH})_{2}$, which has a higher volatility in the presence of steam. Some molybdenum is lost from the catalyst at $700^{\circ} \mathrm{C}$. The decreases in the amount of sulfided cobalt without a decrease in the total cobalt were attributed to interaction between the cobalt and the alumina support at temperatures above $400^{\circ} \mathrm{C}$ in the presence of steam and above $600^{\circ} \mathrm{C}$ in the absence of steam, forming a spinel-like structure.

Han et al. (1992) also investigated the effect of oxidation on the formation of Mo compounds. They noted other studies (Stanislaus et al. 1988; McMillan et al. 1986), which concluded that, under initial calcining of freshly synthesized catalyst or during oxidative regeneration at temperatures above about $700^{\circ} \mathrm{C}$, a portion of the Mo reacts with the aluminum on the $\gamma$-alumina support and forms $\mathrm{Al}_{2}\left(\mathrm{MoO}_{4}\right)_{3}$, which is catalytically inactive. Han et al. showed that this compound is probably amorphous and is easily hydrated as a $\mathrm{MoO}_{3}$ phase at room temperature in $100 \%$ humidity, unlike crystalline $\mathrm{Al}_{2}\left(\mathrm{MoO}_{4}\right)_{3}$.

Jiménez-Mateos et al. (1993) conducted research using fresh and used (in an industrial process) commercial catalyst; subjecting it to regeneration in $7 \% \mathrm{O}_{2}$ in $\mathrm{N}_{2}$ at $400^{\circ} \mathrm{C}$ for $6 \mathrm{hr}$. The used catalyst was previously washed in hexane to remove soluble hydrocarbons. Some used catalysts were subjected to up to 5 regeneration/sulfidation cycles. Under the conditions of regeneration, the surface exposure of molybdenum increased over that in the fresh catalysts and this effect increased with the number of regeneration cycles. The migration of the $\mathrm{MoO}_{3}$ molecules from the crystals to $\mathrm{MoO}_{3}$-free alumina surface was cited as the cause of the increased surface exposure. Nickel showed a slight decrease on the surface after regeneration and a portion of nonsulfidable nickel attributed to the formation of a $\mathrm{NiAl}_{2} \mathrm{O}_{4}$ spinel structure. They also showed that the amount of sulfidable nickel improved with multiple 
regeneration cycles. Sulfate, not present on the fresh catalyst, was found on the used and regenerated catalysts.

Teixeira da Silva et al. (1994) investigated the effects of oxidation sulfidation temperatures on fresh and spent commercial catalyst regeneration. The spent catalyst had been used to hydrotreat shale oil. They found that reoxidation of fresh catalyst at $400^{\circ} \mathrm{C}$ and $500^{\circ} \mathrm{C}$ followed by sulfidation generally increased the reactivity of the resulfided catalyst, with the greatest increase occurring at a $400^{\circ} \mathrm{C}$ oxidation temperature. This increase was attributed to the formation of a $\beta-\mathrm{NiMoO}_{4}$ phase that maintained a structure similar to that of a NiMoS lamellar compound. At $600^{\circ} \mathrm{C}$ the loss of activity was attributed to the formation of a nickel spinel phase $\left(\mathrm{NiAl}_{2} \mathrm{O}_{4}\right)$. Oxidation of the spent catalyst did not restore the activity of the catalyst (about $60 \%$ recovery of activity), even though the regenerated spent catalyst generally possessed the same surface area and pore volume as the fresh catalyst. They also found that for both the oxidized fresh and spent catalysts, resulfidation at about $400^{\circ} \mathrm{C}$ achieved the greatest recovery of activity compared to resulfidation temperatures of either $300^{\circ} \mathrm{C}$ or $500^{\circ} \mathrm{C}$. At a reoxidation temperature of $600^{\circ} \mathrm{C}$, the catalyst was less reactive than the fresh catalyst.

Vanadium also reacts with the zeolite catalyst causing some dealumination through the formation of vanadium aluminum silicate species, and reaction to form rare earth vanadates.

\section{Implications of Catalyst Deactivation on Regeneration Strategies to Remove Metals}

There are a number of implications regarding the deactivation of the various catalysts that can affect the development of a demetallization process to extend the life of the catalyst.

\section{FCC Catalysts}

One of the main concerns with FCC catalysts is the potential for buildup of nickel on the catalyst, which catalyzes dehydrogenation of the feedstock and leads to unacceptable yields of gasoline accompanied by high yields of coke and hydrogen. A secondary consideration is the interactions between the catalyst, deposited metals, and the regeneration gases that cause the catalyst to slowly degrade due to dealumination of the catalyst by vanadium and substitution of the lanthanide with hydrogen. While plugging of the catalyst pores is another consideration, it is less pronounced than the hydrotreating and hydrocracking catalysts because much lower inventories of these metals are achieved in the FCC catalysts at the time the catalyst is replaced.

An important implication of these concerns is that the catalyst cannot be fully restored to its original condition because of the irreversible chemical alteration of the zeolite, particularly with respect to vanadium substitution in the zeolite structure. A second implication is that the undesirable effects of nickel and vanadium in regard to dehydrogenation of the feedstock can be mitigated either by their removal or deactivation. Nickel is by far the more active of the two metals, with activity as much as 10 times more active than that of vanadium.

At present, some refiners add antimony to the feedstock to deactivate the nickel. Tin and magnesium oxide have been used as additives to deactivate the vanadium in some catalysts. One drawback of using additives is that they add to the inventory of metal deposits on the catalyst, which accelerates plugging and makes removal of the metals much more difficult. 


\section{Hydrotreating/Hydrocracking Catalysts}

The primary concern in the deactivation of hydrotreating and hydrocracking catalysts is the gradual accumulation of metals that leads to plugging of the catalyst pores. These metals can account for over $20 \%$ of the spent catalyst weight. Permanent deactivation of the catalyst due to interactions between the support and/or zeolite and the metals and regeneration gases is also a consideration. Even though the catalyst is regenerated very infrequently, minimizing the opportunities for oxidizing the vanadium and for introducing steam into the process, the catalyst life is much longer, providing ample opportunity for this mechanism of catalyst degradation.

The main implication of these considerations regarding metals deposition is that it may not be desirable to remove all of the metal to achieve longer catalyst life. These catalysts already use metals $(\mathrm{Co}, \mathrm{Ni}$, and Mo) to catalyze hydrogenation reactions at high hydrogen partial pressures, so the added nickel and vanadium does not diminish this activity. On the other hand, aggressive removal of deposited metals can result in removing the active cobalt and molybdenum and nickel from the catalyst surfaces. As with the FCC catalysts, removal of the metals from the zeolite catalyst in the hydrotreating catalyst could also impair its stability and cracking activity.

Deactivation due to coke coverage of active sites may not be as critical after the initial accelerated coking stage, and periodic decoking of the catalyst may not be very advantageous if the metals can be removed instead, particularly if the polymeric coke is relatively resistant to oxidation. A consequence of decoking is accelerated migration of active metals and vanadium into the support. The sequence also implies that catalyst regeneration will probably only attain $65 \%$ to $70 \%$ of the original catalyst activity for hydrocracking processes if the pores are completely cleared of metals.

\section{Processes for Demetallization/Catalyst Life Extension}

\section{FCC Catalysts}

Several demetallization processes have been investigated and/or employed commercially for both zeolite and amorphous silica alumina catalysts. All apparently depend on gas phase treatment of the spent catalyst followed by washing with water and ion exchange. One of the more mature processes is the Demet III process. Laboratory-scale treatments based on this process were reported by Elvin et al. (1988). The treatment involved a high-temperature sulfidation step $\left(4 \mathrm{hr}\right.$ at $\left.720^{\circ} \mathrm{C}\right)$ cooled to $320^{\circ} \mathrm{C}$ in nitrogen and then oxidized for $30 \mathrm{~min}$ at this temperature. The catalyst was then cooled to $70^{\circ} \mathrm{C}$ and subjected to two reductive washes ( $\mathrm{SO}_{2}$ bubbled through an aqueous slurry for $5 \mathrm{~min}$ ), followed by two oxidative washes of $2.5 \% \mathrm{H}_{2} \mathrm{O}_{2}(3 \mathrm{~min})$. This last step produces nickel sulfate salts that are soluble in water. Rare earth and ammonium cations may be exchanged onto the catalyst to replace any exchangeable sodium. The laboratory test of the Demet III process accomplished about $80 \mathrm{wt} \%$ nickel removal and $35 \mathrm{wt} \%$ vanadium removal. One modification of this process involved calcination of the catalyst for $4 \mathrm{hr}$ at $730^{\circ} \mathrm{C}$ in air followed by sulfidation for $2 \mathrm{hr}$. After cooling to $320^{\circ} \mathrm{C}$, the catalyst was chlorinated for $1 \mathrm{hr}$. Using the same washing procedures as before, the process reduced nickel by $88 \%$ and the vanadium by $40 \%$. A third method, involving only calcination of the catalyst in air at $720^{\circ} \mathrm{C}$ for $4 \mathrm{hr}$ and followed by the washing steps, did not reduce the nickel content, although the vanadium was reduced by about $35 \%$. The catalyst activity following regeneration showed improved performance, compared to the untreated catalyst, in terms of conversion and gasoline yield. None of the Demet IIIbased processes cause significant reduction in the rare earth or aluminum concentration, mainly because most of the washes are non- or only slightly acidic. 
Some earlier laboratory-scale tests were conducted by Beuther and Flinn (1963) to investigate leaching of FCC catalysts and HDS catalysts (discussed later). Of particular interest was the potential application of oxalic acid to FCC catalyst leaching, because earlier research had suggested aluminum removal was not very pronounced for silica alumina supports. Table A.3 summarizes the results of leaching tests using various leaching times, temperatures, and oxalic acid concentrations on decoked catalyst. These experiments suggest that modest removal of vanadium and nickel occurs relatively rapidly to a certain point and then remains constant. Increasing temperature and/or concentration of oxalic acid improved vanadium removal significantly, while nickel improvements were less. The harsher conditions also resulted in significantly more aluminum removal.

Table A.3. Treatment of FCC Catalyst with Aqueous Oxalic Acid (Beuther and Flinn 1963)

\begin{tabular}{|c|c|c|c|c|c|c|c|c|c|}
\hline \multicolumn{3}{|c|}{ Leaching Treatment } & \multicolumn{4}{|c|}{ Catalyst Properties } & & & \\
\hline $\begin{array}{l}\text { Solution } \\
\text { Conc., }\end{array}$ & Time, hr & Temp., & \multicolumn{3}{|c|}{ Composition, wt. \% } & \multirow{2}{*}{$\begin{array}{c}\text { Surface } \\
\text { Area, } \\
\text { m }^{2} / g\end{array}$} & \multicolumn{3}{|c|}{$\%$ Removal } \\
\hline \multirow{2}{*}{\multicolumn{3}{|c|}{ Contaminated Catalyst }} & $\mathbf{v}$ & $\mathbf{N i}$ & A! & & $\mathbf{V}$ & $\mathbf{N i}$ & $\mathbf{A}$ \\
\hline & & & 0.29 & 0.07 & 16.9 & 49 & - & - & - \\
\hline 0.1 & 12 & 80 & 0.20 & 0.05 & 17.0 & 51 & 31 & 29 & -1 \\
\hline 0.1 & 24 & 80 & 0.18 & 0.05 & 16.8 & 50 & 38 & 29 & 1 \\
\hline 0.1 & 48 & 80 & 0.19 & 0.05 & 16.6 & 49 & 35 & 29 & 2 \\
\hline 1.0 & 12 & 150 & 0.10 & 0.04 & 14.3 & 85 & 66 & 41 & 15 \\
\hline 1.0 & 24 & 150 & 0.12 & 0.05 & 14.0 & 82 & 59 & 29 & 17 \\
\hline 5.0 & 12 & 80 & 0.14 & 0.05 & 15.3 & 62 & 52 & 29 & 10 \\
\hline 5.0 & 24 & 80 & 0.13 & 0.04 & 14.9 & 68 & 55 & 41 & 12 \\
\hline 5.0 & 48 & 80 & 0.14 & 0.04 & 15.6 & 82 & 52 & 41 & 8 \\
\hline
\end{tabular}

\section{Hydrotreating Catalysts}

Beuther and Flinn (1963) investigated selective leaching of nickel and vanadium from a nickel-tungsten on alumina hydrogenation catalyst, a cobalt-molybdenum on alumina hydrotreating catalyst, and a nickelcobalt-molybdenum on alumina hydrodesulfurization catalyst. In all cases the catalyst was decoked prior to treatment. A Ni/W hydrogenation catalyst sample leached with a $1 \mathrm{wt} \%$ oxalic acid solution at $27^{\circ} \mathrm{C}$ removed $54 \mathrm{wt} \%$ and $72 \mathrm{wt} \%$ vanadium from the for 4- and 24-hr leaching times, respectively, while not removing nickel from the hydrogenation catalyst. Interestingly, a series of two 2-hr leachings of the $\mathrm{Ni} / \mathrm{W}$ catalyst, separated by a washing and drying step, achieved $65 \mathrm{wt} \%$ vanadium removal while removing only $5 \mathrm{wt} \%$ of the nickel.

Oxalic acid treatment of a Co/Mo catalyst achieved comparable results regarding $\mathrm{V}$ and $\mathrm{Ni}$ removal. However, the treatment also removed a substantial portion of the molybdenum from the hydrotreating catalyst. 
A series of leaching tests were conducted on a Ni/Co/Mo hydrodesulfurization catalyst using $1 \mathrm{wt} \%$ solutions of a number of organic acids and other organic extractants at $27^{\circ} \mathrm{C}$ with $4 \mathrm{hr}$ of extraction time. These are summarized in Table A.4. Glycolic acid was the only extractant that did not remove molybdenum, although succinic acid only caused a $9 \%$ removal. Of note is that oxalic acid removed $50 \%$ of the nickel from this catalyst, but not for the hydrogenation and hydrotreating catalysts. The spent hydrodesulfurization catalyst was also treated with $1 \%$ aqueous glycolic acid at $93^{\circ} \mathrm{C}$ for $24 \mathrm{hr}$, followed by rinsing and drying, and then tested for desulfurization activity. Table A.5 summarizes the results. Similar results were indicated by Beuther et al. (1980) with the nickel oxide-tungsten oxide-alumina hydrodesulfurization catalyst.

Another process was described in detail for demetallizing hydrodesulfurization catalysts, involving a cobalt-molybdenum (H-oil process) catalyst (Hildebrandt et al. 1993). The approach taken was to leach the catalyst following removal of soluble hydrocarbons but prior to decoking. A $15 \%$ sulfuric acid solution was contacted with the catalyst over a $240-\mathrm{min}$ period, and samples were taken every 10 to

Table A.4. Other Chemicals Capable of Extracting Metal Contaminants (Beuther and Flinn 1963)

\begin{tabular}{|c|c|c|c|c|c|c|c|c|c|}
\hline \multirow{3}{*}{ Chemical Extractant } & \multicolumn{5}{|c|}{ Catalyst Properties } & \multirow{2}{*}{\multicolumn{4}{|c|}{$\begin{array}{c}\text { \% Removal } \\
\text { (parentheses = gain) }\end{array}$}} \\
\hline & \multicolumn{4}{|c|}{ Composition, wt\% } & \multirow{2}{*}{$\begin{array}{c}\text { Surface } \\
\text { Area, } \\
\mathrm{m}^{2} / \mathrm{g}\end{array}$} & & & & \\
\hline & $\mathbf{V}$ & Co & $\mathbf{N i}$ & Mo & & $\mathbf{V}$ & Co & $\mathbf{N i}$ & Mo \\
\hline Fresh Catalyst & 0.0 & 1.0 & 0.5 & 7.7 & 102 & - & -- & --- & -- \\
\hline Spent Catalyst & 1.9 & 1.0 & 0.9 & 7.6 & 92 & -- & -- & -- & -- \\
\hline Oxalic Acid & 1.0 & 0.4 & 0.4 & 3.1 & 109 & 47 & 60 & 56 & 59 \\
\hline Lactic Acid & 1.1 & 0.5 & 0.5 & 4.8 & 106 & 42 & 50 & 44 & 37 \\
\hline Citric Acid - & 1.0 & 0.8 & 0.5 & 6.6 & 107 & 47 & 20 & 44 & 13 \\
\hline Glycolic Acid & 1.2 & 0.8 & 0.7 & 8 & 103 & 37 & 20 & 22 & (5) \\
\hline Phthalic Acid ( $0.5 \%$ soln.) & 1.2 & 0.5 & 0.7 & 6.5 & 104 & 37 & 50 & 22 & 14 \\
\hline Malonic Acid & 1.1 & 0.6 & 0.6 & 5.6 & 105 & 42 & 40 & 33 & 26 \\
\hline Succinic Acid & 1.3 & 0.8 & 0.8 & 6.9 & 99 & 32 & 20 & 11 & 9 \\
\hline Salicylic Acid & 1.2 & 1.1 & 0.7 & 5.4 & 101 & 37 & (10) & 22 & 29 \\
\hline Tartaric Acid & 1.2 & 0.4 & 0.5 & 3.6 & 108 & 37 & 60 & 44 & 53 \\
\hline Salicylaldehyde & 1.3 & 0.9 & 0.8 & 5.4 & 100 & 32 & 10 & 11 & 29 \\
\hline o- Amino phenol & 1.4 & 1.2 & 0.8 & 5.4 & 99 & 24 & (20) & 11 & 29 \\
\hline EthyleneDiamine & 1.2 & 1.1 & 0.7 & 5.2 & 101 & 38 & (10) & 22 & 32 \\
\hline Acetalacetone & 1.4 & 0.8 & 0.8 & 4.9 & 105 & 29 & 20 & 11 & 35 \\
\hline
\end{tabular}


Table A.5. Effect of Glycolic Acid Leaching on the Activity of a Hydrodesulfurization Catalyst

\begin{tabular}{|l|l|l|l|}
\hline \multirow{2}{*}{ Contaminant, wt\% } & \multicolumn{3}{|c|}{ NiCoMo Catalyst } \\
\cline { 2 - 4 } & Fresh & Spent & Regenerated \\
\hline $\mathrm{V}$ & - & 12.5 & 4.6 \\
\hline $\mathrm{Ni}$ & 0.5 & 3.3 & 1.6 \\
\hline Desulfurization $\mathrm{wt} \%$ & 87 & 64 & 81 \\
\hline
\end{tabular}

$20 \mathrm{~min}$. None of the molybdenum and only $30 \%$ of the aluminum was removed over the full period, while $91 \%$ of the nickel and $46 \%$ of the vanadium was removed. Furthermore, selectivity towards nickel and vanadium removal was very pronounced at the beginning of the leaching period, with $80 \%$ of the nickel and $40 \%$ of the vanadium removed compared to only $12 \%$ of the aluminum removed after about $80 \mathrm{~min}$. The crush strength was only partially lost and still at acceptable levels at these conditions. Also, the catalytic activity of the regenerated catalyst (including decoking) was very comparable to fresh. catalyst over a 15-day test period.

Weisser and Landa (1973) mentioned a German Patent (No.1,040,723, Retailliau, E. R. 1958) for treatment of a cobalt-molybdenum catalyst with ammonium sulfide to remove vanadium. They also mentioned that vanadium may be removed, in part, with the aid of some complex forming acids or hydroxyacids.

Silbernagel et al. (1984) conducted tests using molybdophosphoric acid (MPA) at pH of about 2. At this $\mathrm{pH}$, the acid is in the form of $\mathrm{H}_{3} \mathrm{PMo}_{12} \mathrm{O}_{40} \cdot \mathrm{xH}_{2} \mathrm{O}$. Extractions were conducted for several days at $45^{\circ} \mathrm{C}$ using a $0.4 \mathrm{wt} \%$ acid solution. Table A.6 summarizes the results.

Table A.6. Results of MPA Extraction of a Large Pore and a Small Pore Co-Mo-Alumina HDS Catalyst

\begin{tabular}{|c|c|c|c|c|c|}
\hline \multirow{2}{*}{$\begin{array}{c}\text { Spent } \\
\text { Catalysts }\end{array}$} & Vanadium & Nickel & Cobalt & Molybdenum & Aluminum \\
\cline { 2 - 5 } & $70-80$ & $\sim 98$ & -45 & 0 & 0 \\
\hline $\begin{array}{c}\text { Small Pore } \\
(\mathrm{d} \sim 50 \AA)\end{array}$ & $70-80$ & 93 & -40 & 0 & 0 \\
\hline $\begin{array}{c}\text { Large Pore } \\
(\mathrm{d} \sim 150 \AA)\end{array}$ & & & & 0 \\
\hline
\end{tabular}

The extraction showed excellent vanadium and nickel removal without causing any loss of molybdenum or aluminum. NMR and ESR analysis showed that the vanadium sulfide was removed, while only a portion of the diamagnetic and none of the $\mathrm{VO}^{+2}$ was removed. Silbernagel et al. (1984) noted other research that showed sulfidation of all the vanadium with $\mathrm{H}_{2} \mathrm{~S}$ at $500^{\circ} \mathrm{C}$ to $600^{\circ} \mathrm{C}$ for several hours provided for complete removal of the vanadium. They also cited their earlier work that showed the extraction rate can be dramatically enhanced by the addition of $\mathrm{H}_{2} \mathrm{O}_{2}$ to the MPA solution. 
Gamble and Levy (U.S. Patent No. 4024815) proposed that for the selective removal of coke and vanadium from $\mathrm{CoMo} / \mathrm{Al}_{2} \mathrm{O}_{3}$ catalyst the samples should be heated in a sulfurous atmosphere (e.g., $10 \%$ $\mathrm{H}_{2} \mathrm{~S} / \mathrm{H}_{2}$ ) at $400^{\circ} \mathrm{C}$ to $825^{\circ} \mathrm{C}$ for up to 1 week. Removal of coke and vanadium was facilitated by the volatilization of the sulfides. In one set of experiments, a 4-day treatment reduced vanadium concentration from $7 \%$ to $1 \%$ and recovered the catalyst activity from $40 \%$ to $65 \%$ of the activity of the virgin catalyst. No removal of cobalt or molybdenum occurred during treatment. Silbernagel et al. (U.S. Patent No 4272400$)$ added an acid ( $0.2 \%$ to $6 \%$ metal heteropoly acid) or $\mathrm{H}_{2} \mathrm{O}_{2}$ leach for 2 to $200 \mathrm{hr}$ after the sulfurous atmosphere treatment. Cobalt or nickel was added to the catalyst by impregnation, which was then calcined. Up to $97 \%$ vanadium, $90 \%$ nickel, and $50 \%$ cobalt were removed using this procedure, and essentially $100 \%$ of the catalyst activity was reported (Hiltzik 1987).

Another approach proposed by Ganguli (U. S. Patent No. 4454240) used a 5\% to 50\% sulfuric acid leach containing $0 \%$ to $10 \% \mathrm{NH}_{4}{ }^{+}$for 5 to $120 \mathrm{~min}$, prior to calcining the spent catalyst to remove coke. Before the leach, the catalyst was solvent-washed to removed soluble oils, followed by a water wash to fill the pores with water. Following the treatment and subsequent calcining, the surface area of the treated catalyst had increased from 128 to $235 \mathrm{~m}^{2} / \mathrm{g}$, as compared to $339 \mathrm{~m}^{2} / \mathrm{g}$ of the virgin material. The catalyst, which was used in coal processing, was reported to have its activity restored to virgin catalyst levels.

\section{Implications of Earlier Leaching Experiments}

Hiltzik (1987) reported several studies that investigated leaching techniques as a method for characterizing catalyst surfaces species. These experiments provide clues regarding the impact of partial removal on catalyst activity.

Kotera et al. (1971) showed that $\mathrm{CoMo} / \mathrm{Al}_{2} \mathrm{O}_{3}$ catalyst samples could be leached with $3 \% \mathrm{NH}_{4} \mathrm{OH}$ to remove $50 \%$ of the molybdenum, regardless of the initial loading, with no effect on the catalyst activity. This suggested that an unpromoted, low-activity Mo phase on the catalyst could easily and selectively be removed. A later study by Gil-Llambias et al. (1984), using a similar leaching procedure, showed the extracted Mo was multi-layer octahedral Mo(IV). The retained species was monolayer species associated with the alumina and similar to $\mathrm{Al}_{2}\left(\mathrm{MO}_{4}\right)_{3}$.

Morales et al. (1983) investigated the effects of a $2 \mathrm{wt} \%$ tartaric acid leach on calcined $\mathrm{CoMo} / \mathrm{Al}_{2} \mathrm{O}_{3}$ and $\mathrm{Mo} / \mathrm{Al}_{2} \mathrm{O}_{3}$ catalyst. The treatment removed $66 \% \mathrm{Mo}$ and $50 \% \mathrm{Co}$, and $50 \% \mathrm{Mo}$, respectively. The process redispersed the remaining metals, with Co enhancing Mo dispersion. The activity of the resulfided treated catalysts was improved for HDS and maintained the same for HDV.

Hiltzik (1987) also reported research in which leaching was used in a study of a $\mathrm{NiMo} / \mathrm{Al}_{2} \mathrm{O}_{3}$ catalyst used in thiophene reactions. Three types of nickel were identified: alumina-bound nickel that was not extractable, nickel that was extractable from the oxide catalyst and had a low HDS activity, and nickel that was HDS active and was only extractable from the sulfided catalyst. It was also concluded that sulfidation caused $\mathrm{Ni}^{+2}$ to migrate to the alumina surface, which increased its removal, whereas calcination sent the $\mathrm{Ni}^{+2}$ into the support, which reduced the ease of nickel dissolution.

Hiltzik reported work done by Bachelier et al. (1983), who evaluated the leaching of a $\mathrm{Mo} / \mathrm{Al}_{2} \mathrm{O}_{3}$ catalyst and a $\mathrm{CoMo} / \mathrm{Al}_{2} \mathrm{O}_{3}$ catalyst in both the oxide and sulfide form. Although the leaching rates were slower for the sulfided catalyst, the maximum removal $(66 \%)$ was the same. The leached and unleached samples had the same thiophene HDS activity and chemisorbed oxygen uptake, indicating that the active site environment was not affected by leaching. 
Hiltzik conducted research on the regeneration of HDS catalysts using a ferric ion leaching procedure. He showed that the acid content of the leaching solution controlled the aluminum removal rate, but that the presence of coke on the catalyst appeared to act as a barrier to dissolution. The ferric ion concentration had no effect on aluminum dissolution. Molybdenum dissolution was reduced by sulfidation pretreatment and sometimes by the presence of coke on the catalyst. Molybdenum dissolution was increased by increasing the ferric ion concentration. Cobait and nickel were both strongly affected by the ferric ion concentration. Vanadium dissolution was similarly affected by the ferric ion concentration, but removing large quantities of vanadium required presulfidation. In the study, a 5 vol\% sulfuric acid concentration was used to keep the ferric ion in solution. Sulfidation at $540^{\circ} \mathrm{C}$ for $16 \mathrm{hr}$ was necessary to reduce $\mathrm{Mo}$ and $\mathrm{Al}$ removal rates to an acceptable level. At the same time, sulfidation increased the selective removal of the foulant metals. The combination of sulfidation and leach treatment removed $50 \%$ to $70 \%$ of the foulant metals while retaining $80 \%$ to $90 \%$ of the $\mathrm{Mo} / \mathrm{AL}_{2} \mathrm{O}_{3}$ components. Treatment of spent refinery fouled catalysts using the sulfidation/leaching sequence, followed by calcination to remove recovered catalyst, recovered from $25 \%$ to between $36 \%$ and $48 \%$ of virgin catalyst HDS activity, and from $25 \%$ to between $74 \%$ and $86 \%$ hydrogenation activity.

\section{Other Related Research}

Noguchi et al. (1993) investigated the effect of the degree of decoking on the valence of vanadium on the regenerated catalyst. They found that less than about $85 \%$ of the vanadium was oxidized until the residual coke was less than about $0.8 \%$ (for a spent catalyst with about $20 \%$ coke on it). The reduced form of vanadium did not appear to adversely affect the catalyst. The amount of molybdenum on the catalyst, catalyst surface areas, and catalyst activities decreased only slightly. On the other hand, when the vanadium was oxidized during decoking the catalyst was significantly damaged. Noguchi et al. also showed that when steam is introduced during regeneration, the surface area of the catalyst reduces to about half of its original value.

\section{References}

Arteaga, a., J. L.G. Fierro, P. Grange and B. Delmon. 1987. "Simulated Regeneration of an Industrial $\mathrm{CoMo} / \gamma-\mathrm{Al}_{2} \mathrm{O}_{3}$ Catalyst, Influence of Steam." Symposium on Advances in Hydrotreating. Presented before the Divison of Petroleum Chemistry, Inc. American Chemical Society, Denver Meeting, April 5$8,1987$.

Bartholomew, C. H. 1994. "Catalyst Deactivation in Hydrotreating Of Residua: a Review." In Catalytic Hydroprocessing of Petroleum and Distillates, Ed. Oballa, M. C. and Shih, S. S., Marcel Dekker, Inc., New York.

Bachelier, J. C., J. C. Duchet, and D. Cornet. 1984. Journal of Catalysis 87:283-291.

Beuther, H. and R. A. Flinn. 1963. "Technique for Removing Metal contaminants from Catalysts," I\&EC Product Research and Development 2(1):53-57.

Beuther, H. O., A. Larson, A. J. Perrotta. 1980. In Catalyst Deactivation, eds. B. Delmon and G. Froment, Elsevier, 271.

Bland, W. F. and B. L. Davidson. 1967. Petroleum Processing Handbook. Von Nostrand, Princeton, New Jersey. 
Cumming, K. A. and B. W. Wojciechowski. 1996. "Hydrogen Transfer, Coke Formation, and Catalyst Decay and Their Role in the Chain Mechanism of Catalytic Cracking," Catal. Rev. - Sci. Eng. 38(1)101157.

Elvin, F. J., J. E. Otterstedt and J. Sterte. 1988. "Process for Demetallization of Fluid Cracking Catalysts." In Fluid Catalytic Cracking Role in Modern Refining. M. L. Occelli, Ed. American Chemical society, Washington D. C.

Fleisch, T. H. B. L. Meyers, J. B. Hall, and G. L. Ott. 1984. Journal of Catalysis 86:111-115.

Gambel, F. R. and R. B. Levey, U.S. Patent No., 4,014,815.

Ganguli, P. S. U. S. Patent No. 4,454,240.

Gil-Llambias, F. J., A. M. Escudy-Castro, A. Lopez-Agudo, and J. L. Garcia-Fierro. 1984. Journal of Catalysis 90:323-328.

Han, O. H., C. Y. Lin, and G. L. Haller. 1992. "Hydration Effects of $\mathrm{Al}_{2}\left(\mathrm{MoO}_{4}\right)_{3}$ and $\mathrm{AlPO}_{4}$ Phases in Hydrotreating Catalysts Studied by Solid State Nuclear Magnetic Resonance Spectroscopy." Catalyst Letters 14:1-9.

Hatch, L. F. and S Matar. 1981. "From Hydrocarbons to Petrochemicals." Gulf Publishing Company, Houston.

Hildebrandt, S. J., R. O Kŏseoglu, and J. E. Duddy. 1993. "Rejuvenation and Reuse of High-Activity Catalyst for Hydroprocessing High Metals Residue," In Proceedings of the Symposium on Regeneration, Reactivation and Reworking of Spent Catalysts Presented before the Division of Petroleum Chemistry, Inc. American Chemical Society, Washington D. C.

Hiltzik, L. H. 1987. Characterization of a Catalyst Regeneration Process for Metals Fouled $\mathrm{CoMo} / \mathrm{Al}_{2} \mathrm{O}_{3}$ Catalysts. Ph.D. Thesis, Georgia Institute of Technology.

Jiménez-Mateos, J. M. Trejo, S. Vic, B. Pawelec, and J. L. G. Fierro. 1993. "Regeneration of an Industrial Hydrotreating Catalyst Used for Long Time On-Stream." Symposium on Regeneration , Reactivation and Reworking of Spent Catalysts, Presented Before the Division of Petroleum Chemistry, Inc. $205^{\text {th }}$ National Meeting, American Chemical Society, Denver, Colorado, March 28-April 2, 1993.

Kotera, Y., N. Todo, K. Muramatsu, K. Ogawa, and K. Tanabe. 1971. International Chemical Engineering 11:752.

Massoth, F. E., G. Muralidhar, and J. Shabtai. 1984. Journal of Catalysis 85:53-62.

McCulloch, D.C. 1983. "Catalytic Hydrotreating in Petroleum Refining," In Applied Industrial Catalysis. Ed. B. E. Leach, Academic Press.

McMillan, M., J. S. Brinen, and G. L. Haller. 1986. Journal of Catalysis 97:243.

Morales, A., N. P. Martinez, J. Laine, E. Payen, and J. Grimblot. 1983. Applied Catalysis 6:329-340. 
Noguchi, Y., Y. Itoh, Y. Obayashi and K. Komine. 1993. "Regeneration of Heavy Oil Hydrotreating Catalyst." Symposium on Regeneration, Reactivation and Reworking of Spent Catalysts. 205th National Meeting American Chemical Society- Division of Petroleum Chemistry, 38(1):50-53.

Oballa, M. C. and S. S. Shih. 1994. "Catalytic Hydroprocessing of Petroleum and Distillates." Marcel Dekker, Inc., New York.

Occelli, M. L. 1988. "Recent Trends in Fluid Catalytic Cracking," In Fluid Catalytic Cracking Role in Modern Refining. M. L. Occelli, Ed. American Chemical society, Washington D. C.

Pratt, K. C. , J. V. Sanders, and V. Tamp. 1980. Journal of Catalysis 66:82-92.

Prins, R., V. H. J. De Beer and G. a. Somorjai. 1989. "Structure and Function of the Catalyst and the Promotoer in Co-Mo Hydrodesulfurization Catalysts," Catalyst Rev.-Sci. Eng. 31(1\&2):1-41.

Rankel, L. A. and L. D. Rollmann. 1983. Fuel 62:44-47.

Retailliau, E. R. 1958. German Patent No. 1040723.

Schuetze, B. and H. Hoffman. 1984. "How to Upgrade Heavy Feeds." Hydrocarbon Processing 63(2):75-82.

Silbernagel, B. G. 1979. Journal of Catalysis 56:315-320.

Silbernagel, B. G., R. R. Mohan, and G. H. Singal. 1984. "Magnetic Resonance Studies of Metal Deposition on Hydrotreating Catalysts and Removal with Heteropolyacids," T. D. White, Jr., R. A. Dalla Betta, E.G. Derouane, R. T. K. Baker, Eds. Catalytic Materials Relationship Between Structure and Reactivity. American Chemical Society, Washington D. C.

Stanley, S. F. 1988. "Preparational Factors and Characterization of $\mathrm{Ni}-\mathrm{Mo}-\mathrm{Al}_{2} \mathrm{O}_{3}$ Hydrotreating Catalysts." Thesis, Department of Chemical Engineering, University of Houston, Texas.

Stanislaus, A., M. Absi-Halabi, K. Al-Dolama. 1988. Applied Catalysis 39:239.

Teixeira da Silva, V. L. S., R Frety, and Martin Schmal. 1994. "Activation and Regeneration of a $\mathrm{NiMo} / \mathrm{Al}_{2} \mathrm{O}_{4}$ Hydrotreatment Catalyst," Ind. Eng. Chem. Res. 33:1992-1699.

Venuto, P. B. and E. T. Habib, J. 1979. "Fluid Catalytic Cracking with Zeolites." Marcel Dekker, Inc., New York.

Weisser, O. and S. Landa. 1973. Sulphide Catalysts, Their Properties and Applications. Pergamon Press, New York. 